\title{
Solar geoengineering using solid aerosol in the stratosphere
}

\author{
D. K. Weisenstein ${ }^{1}$, D. W. Keith ${ }^{1,2}$, and J. A. Dykema ${ }^{1}$ \\ ${ }^{1}$ School of Engineering and Applied Science, Harvard University, Cambridge, MA, USA \\ ${ }^{2}$ Kennedy School of Government, Harvard University, Cambridge, MA, USA
}

Correspondence to: D. K. Weisenstein (dkweis@ seas.harvard.edu)

Received: 10 March 2015 - Published in Atmos. Chem. Phys. Discuss.: 21 April 2015

Revised: 7 October 2015 - Accepted: 14 October 2015 - Published: 26 October 2015

\begin{abstract}
Solid aerosol particles have long been proposed as an alternative to sulfate aerosols for solar geoengineering. Any solid aerosol introduced into the stratosphere would be subject to coagulation with itself, producing fractal aggregates, and with the natural sulfate aerosol, producing liquidcoated solids. Solid aerosols that are coated with sulfate and/or have formed aggregates may have very different scattering properties and chemical behavior than uncoated nonaggregated monomers do. We use a two-dimensional (2-D) chemistry-transport-aerosol model to capture the dynamics of interacting solid and liquid aerosols in the stratosphere. As an example, we apply the model to the possible use of alumina and diamond particles for solar geoengineering. For $240 \mathrm{~nm}$ radius alumina particles, for example, an injection rate of $4 \mathrm{Tg} \mathrm{yr}^{-1}$ produces a global-average shortwave radiative forcing of $-1.2 \mathrm{~W} \mathrm{~m}^{-2}$ and minimal self-coagulation of alumina although almost all alumina outside the tropics is coated with sulfate. For the same radiative forcing, these solid aerosols can produce less ozone loss, less stratospheric heating, and less forward scattering than sulfate aerosols do. Our results suggest that appropriately sized alumina, diamond or similar high-index particles may have less severe technology-specific risks than sulfate aerosols do. These results, particularly the ozone response, are subject to large uncertainties due to the limited data on the rate constants of reactions on the dry surfaces.
\end{abstract}

\section{Introduction}

Solar geoengineering, or solar radiation management (SRM) has the possibility of deliberately introducing changes to the Earth's radiative balance to partially offset the radiative forcing of accumulating greenhouse gases and so lessen the risks of climate change. Most research on SRM has concentrated on the possibility of adding aerosols to the stratosphere, and essentially all atmospheric modeling of stratospheric aerosol injection has focused on increasing the loading of aqueous sulfuric acid aerosols (Rasch et al., 2008; Heckendorn et al., 2009; Niemeier et al., 2011; Pitari et al., 2014). The possibility that solid aerosol particles might offer advantages over sulfates, such as improved scattering properties, was first suggested almost 2 decades ago, but analysis has been almost exclusively limited to conceptual studies or simple radiative transfer models (Teller et al., 1997; Blackstock et al., 2009; Keith, 2010; Ferraro et al., 2011; Pope et al., 2012).

Any solid aerosol injected directly into the stratosphere for geoengineering purposes would be subject to coagulation with itself and with the natural background or volcanic sulfate aerosol. Aggregates of solid aerosols have very different physical structure and scattering properties than liquid sulfate aerosol particles do. The lifetime and scattering properties of a solid aerosol are strongly dependent on these dynamical interactions, and the chemical properties of the aerosol depend on the extent to which it becomes coated by the ambient sulfate.

We have modified the Atmospheric and Environmental Research (AER) two-dimensional (2-D) chemistrytransport-aerosol model (Weisenstein et al., 2004, 2007) to capture the dynamics of interacting solid and liquid aerosols in the stratosphere. Our model now includes a prognostic size distribution for three categories of aerosols: liquid aerosols, solid aerosols, and liquid-coated solid aerosols. The model's coalescence kernel has been modified and extended to parameterize the interactions of particles across size bins and between all combinations of the three categories. The surface area, sedimentation speed, and coalescence cross section of an aggregate of solid particles depend on the geometry of 
the aggregate. The model parameterizes this physics using a fractal dimension and allows that fractal dimension to change with age or with a liquid coating. The chemistry and aerosol schemes in the model are interactive, while dynamical fields are prescribed.

Turning now to the context of this work, it is useful to divide overall consideration of the risks and efficacy of SRM into two components. First, the ability, or efficacy, of idealized SRM - conceived as a reduction in the solar constant - to compensate for the risks of accumulating greenhouse gases and, second, the technology-specific risks of any specific engineered intervention that produces a change in radiative forcing. Uncertainty in the efficacy of SRM, the first component, rests on uncertainty in the climate's large-scale response to forcing. Results from a large set of climate models suggest that idealized SRM can do a surprisingly good job in reducing model-simulated climate changes, both locally and globally, which, in our view, is a primary motivation for continued research on SRM (Kravitz et al., 2014; MorenoCruz et al., 2011).

Evaluation of the technology-specific risks depends on the specific technology. For sulfate aerosols these risks include, but are not limited to, (a) ozone loss, (b) radiative heating of the lower stratosphere which causes changes in atmospheric temperature and dynamical transport, and (c) the fact that sulfates produce a relatively high ratio of downward scattering to upward scattering so that they substantially increase the ratio of diffuse to direct radiation (Kravitz et al., 2012) which in turn may alter atmospheric chemistry and ecosystem functioning (Mercado et al., 2009; Wilton et al., 2011). In addition to the risks, it may be difficult to produce sufficiently large radiative forcings using $\mathrm{SO}_{2}$ because of the decreasing efficiency at higher $\mathrm{SO}_{2}$ inputs (Heckendorn et al., 2009; English et al., 2012).

The use of solid particles for SRM offers the potential to address all of the limitations of sulfate particles. Solid aerosols do not, for example, directly increase the stratospheric volume of the aqueous sulfuric acid that drives hydrolysis reactions, an important pathway through which sulfate aerosols cause ozone loss. In addition, some solid aerosols (e.g., diamond, alumina, or titania) have optical properties that may produce less heating in the lower stratosphere (Ferraro et al., 2011), and any solid with a high index of refraction can reduce forward scattering.

The use of solid aerosols, however, introduces new risks that require evaluation. The dry surfaces of the solid aerosols, for example, may catalyze reactions that cause ozone loss (Tang et al., 2014a, b). This risk is hard to evaluate because the rates of many potentially important chemical reactions remain unmeasured for substances such as diamond that are novel in the stratosphere. Moreover, by spreading the natural background sulfuric acid over a larger surface area as will occur when background sulfate coats the solid particles, the addition of solid aerosols will increase reactions that depend on sulfate surface area density rather than sulfate volume.
Our motivation for studying solid particles is the possibility that they enable a decrease in the risks of SRM (e.g., ozone loss) or an increase in its efficacy such as the ability to produce larger radiative forcings, or an improved ability to "tune" the spectral or spatial characteristics of the radiative forcing (Blackstock et al., 2009; Keith, 2010). This is in contrast to much of the prior literature that has focused on the potential of solid particles to deliver higher mass-specific scattering efficiency, thus reducing the amount of material needed to produce a given radiative forcing. We do not see this as an important motivation as it appears that the cost of lofting materials to the stratosphere is sufficiently low that cost is not an important barrier to implementation of SRM (McClellan et al., 2012).

In this paper, our focus is on developing the tools and methodology for assessing the risks and performance of solid particles injected into the stratosphere for SRM. The tool described here is a new solid-liquid stratospheric aerosol model, and the methodology is a comparison of environmental side effects such as ozone loss and forward scattering as a function of the global radiative forcing. We use aluminum oxide (alumina) aerosol as the primary example. Diamond appears to be superior to alumina in several respects, perhaps the most important being that it has minimal absorption in the thermal infrared. We examine diamond, but choose alumina as the primary example because there is a broad basis to examine alumina's potential environmental impacts. Unlike many other solid particles proposed for SRM, there is prior work examining alumina's impacts on stratospheric chemistry (Danilin et al., 2001; Jackman et al., 1998; Ross and Sheaffer, 2014), work that was produced from NASAfunded studies starting in the late 1970's motivated by concerns about the ozone impact of space shuttle launches (alumina is a major component of the shuttle's solid rocket exhaust plume). Moreover, alumina is a common industrial material with a high index of refraction for which there is substantial industrial experience with the production of nanoparticles (Hinklin et al., 2004; Tsuzuki and McCormick, 2004). With respect to potential environmental impacts of alumina deposition on Earth's surface, the fact that aluminum oxides are a common component of natural mineral dust deposition provides a basis for assessing impacts (Lawrence and Neff, 2009). For diamond, there is evidence that diamond nanoparticles are nontoxic to biological systems (Shrand et al., 2007). A much more substantive assessment of the human health and ecosystems impacts of any proposed solid aerosol would be required, however, prior to serious consideration of their use for geoengineering.

The remainder of this paper is organized as follows: the solid-liquid model is presented in Sect. 2, results for geoengineering injection of alumina and diamond in Sect. 3, and discussion in Sect. 4. 


\section{Aerosol model}

We have incorporated solid aerosols into the AER 2-D chemistry-transport-aerosol model (Weisenstein et al., 1997, 2004, 2007). The aerosol module, which employs a sectional scheme, has been modified to include three separate classes of aerosols, each with its own size distribution: solid particles, liquid $\mathrm{H}_{2} \mathrm{SO}_{4}-\mathrm{H}_{2} \mathrm{O}$ particles, and mixed solid-liquid particles. To fully specify the mixed particles we keep track of the volume of liquid $\mathrm{H}_{2} \mathrm{SO}_{4}-\mathrm{H}_{2} \mathrm{O}$ solution coating the mixed particles. Unlike liquid particles that coagulate into larger spheres, solid particles coagulate into fractal structures with more complex properties. The fractal properties are required to predict the effective size of the particles appropriate to determining coagulation interactions and gravitational settling. Fractal properties are also needed to determine the condensation rate of $\mathrm{H}_{2} \mathrm{SO}_{4}$ gas onto alumina particles and the aerosol surface area density that is important to heterogeneous chemistry and ozone depletion.

The AER 2-D model includes standard chemistry relevant to ozone (Weisenstein et al., 2004) as well as aerosol microphysics, and the relevant sulfur chemistry (Weisenstein et al., 1997, 2007). The model includes sulfur-bearing source gases dimethyl sulfide (DMS), $\mathrm{CS}_{2}, \mathrm{H}_{2} \mathrm{~S}$, OCS, and $\mathrm{SO}_{2}$ emitted by industrial and biogenic processes as well as the product gases methyl sulfonic acid (MSA), $\mathrm{SO}_{2}, \mathrm{SO}_{3}$, and $\mathrm{H}_{2} \mathrm{SO}_{4}$. Chemical reactions affecting sulfur species are listed in Weisenstein et al. (1997) and their rates have been updated according to Sander et al. (2011). Values of $\mathrm{OH}$ and other oxidants are calculated interactively along with ozone and aerosols (Rinsland et al., 2003; Weisenstein et al., 2004). Further description of the chemistry directly relevant to ozone is included in Sect. 3.5. The model's 2-D transport is prescribed based on calculations by Fleming et al. (1999) for each year from 1978 to 2004, employing observed temperature, ozone, water vapor, zonal wind, and planetary waves. Different phases of the quasi-biennial oscillation (QBO) are included in the observational data employed. We average the transport fields over the years 1978-2004 into a climatology and employ that circulation each year of our 10-year calculations. Temperature fields are also prescribed based on climatological observations for the same averaging period. The domain is global, from the surface to $60 \mathrm{~km}$, with resolution of $1.2 \mathrm{~km}$ in the vertical and $9.5^{\circ}$ in latitude. Though the model is primarily suited to modeling the stratosphere and upper troposphere, it does contain a parameterization of tropospheric convection (Dvortsov et al., 1998) that serves to elevate $\mathrm{SO}_{2}$ concentrations in the tropical upper troposphere.

The AER 2-D aerosol model, along with several other 2-D and 3-D models, was evaluated and compared to observations in SPARC (2006). The AER model was found to reasonably represent stratospheric aerosol observations in both nonvolcanic conditions and in the period following the eruption of Mt. Pinatubo. Noted deficiencies, common to most models, included values of aerosol extinction in the tropics calculated to be too high between the tropopause and $25 \mathrm{~km}$ as compared to SAGE II extinctions at 0.525 and $1.02 \mu \mathrm{m}$ during nonvolcanic periods. The growth and decay of the stratospheric aerosol layer following the Mt. Pinatubo eruptions was generally well-represented by the AER model as compared to lidar and satellite observations from 1991 to 1997 , though uncertainties in the initial $\mathrm{SO}_{2}$ injection amount and vertical distribution limit our interpretation. Dynamical variability on short timescales was underestimated by the model.

Sulfate aerosol formation is thought to be initiated mainly by binary homogeneous nucleation of $\mathrm{H}_{2} \mathrm{SO}_{4}$ and $\mathrm{H}_{2} \mathrm{O}$ vapors, primarily in the tropical tropopause region. The aerosol size distribution is modified by condensation and evaporation of gas-phase $\mathrm{H}_{2} \mathrm{SO}_{4}$ and by coagulation among particles (Brock et al., 1995; Hamill et al., 1997). Sulfate aerosol particles are assumed to be liquid spheres with equilibrium composition $\left(\mathrm{H}_{2} \mathrm{SO}_{4}\right.$ and $\mathrm{H}_{2} \mathrm{O}$ fractions) determined by the local grid box temperature and water vapor concentration (Tabazadeh et al., 1997). The model uses a sectional representation of particle sizes, with 40 logarithmically spaced sulfate aerosol bins, representing sizes from $0.39 \mathrm{~nm}$ to $3.2 \mu \mathrm{m}$, with aerosol volume doubled between adjacent bins. Particle distributions are also modified by sedimentation and by rainout/washout processes in the troposphere. The sedimentation formulation is described below. Rainout/washout process are represent by a first-order loss term in the troposphere with removal lifetime ranging from 5 days at the surface to 30 days at the tropopause.

Solid particles are modeled with a similar sectional representation; in this case it is the number of monomers per particle that is doubled in successive bins. Only the monomers, the primary particles directly injected into the atmosphere, are assumed to be spherical. Larger particles produced by coagulation assume fractal structures that obey a statistical scaling law where the fractal dimension $D_{\mathrm{f}}$ determines how the size of an aggregate of particles is related to the number of primary particles (Filippov et al., 2000; Maricq, 2007). The radius of gyration $R_{\mathrm{g}}$ of a fractal (the root-mean-square distance from the center of mass) is given by

$R_{\mathrm{g}}=R_{0}\left(N_{i} / k_{\mathrm{f}}\right)^{\left(1 / D_{\mathrm{f}}\right)}$,

where $R_{0}$ is the primary particle radius, $N_{i}$ the number of monomers in the fractal of bin $i$, and $k_{\mathrm{f}}$ is a prefactor. Thus particle mass is proportional to $R_{\mathrm{g}}^{D_{\mathrm{f}}}$. The fractal dimension $D_{\mathrm{f}}$ for a given material has been found to be invariant for a wide range of $R_{0}$ and $N_{i}$ values.

The surface area $(S)$ for a fractal particle can be parameterized with an effective radius $R_{\text {eff }}$ which can be related to primary radius and the number of monomer cores in the particle: 
$R_{\text {eff }}=R_{0}\left(N_{i} / k_{h}\right)^{\left(1 / D_{h}\right)}$

$S_{i}=\left(4 \pi R_{0}^{2}\right) \times\left(N_{i} / k_{h}\right)^{\left(2 / D_{h}\right)}$,

where $D_{h}$ and $k_{h}$ are the scaling exponent and prefactor specific to surface transfer processes. With fractal dimension $D_{\mathrm{f}}<2.0, D_{h}$ can be assumed to be equal to 2.0. With $D_{\mathrm{f}}>2.0, D_{h}$ can be assumed to be equal to $D_{\mathrm{f}}$ (Filippov et al., 2000). When $D_{h}=2.0$, the surface area of a fractal particle is equal to the surface area of the monomer multiplied by the number of monomers in the aggregate. This formalism is most appropriate for large values of $N_{i}$ (i.e., greater than 100). For consistency at small values of $N_{i}$, we assume that $k_{\mathrm{f}}=k_{h}=1$, since we find that simulations producing only small $N_{i}$ values are most efficient for geoengineering.

The solid particles are allowed to interact with background stratospheric sulfate particles by coagulation, and with gasphase $\mathrm{H}_{2} \mathrm{SO}_{4}$ and $\mathrm{H}_{2} \mathrm{O}$ by condensation and evaporation. We use $R_{\mathrm{g}}$ as the particle radius when calculating the coagulation kernel, the probability that two particles will combine into one on collision (Maricq, 2007). The coagulation formulation between and among different particle types is detailed in Appendix A. The condensation rate, also detailed in Appendix A, depends on particle surface area, and secondarily, on a radius of curvature for the Kelvin correction. We use $R_{0}$ as the radius-of-curvature in the condensation equation, since gas molecules see the individual monomers making up the fractal. We model mixed-phase particles by tracking particle number per bin and mass of $\mathrm{H}_{2} \mathrm{SO}_{4}$ per bin in the mixed particles. Volume and surface area of the mixed particles depends also on the $\mathrm{H}_{2} \mathrm{O}$ present in the equilibrium $\mathrm{H}_{2} \mathrm{SO}_{4}-$ $\mathrm{H}_{2} \mathrm{O}$ solution. Above about $35 \mathrm{~km}$, coated particles will lose their sulfate coating by evaporation and become dry again.

The sedimentation velocity of fractal particles represents a balance between the gravitational force, proportional to particle mass, $M_{\mathrm{p}}$, and the drag force, proportional to the particle velocity and the 2-D surface area projection of the particle, $A_{2-\mathrm{D}}$, and inversely proportional to the particle radius $R_{\mathrm{p}}$. Sedimentation velocity is modified by the Cunningham slipflow correction, $G$, which accounts for larger sedimentation velocities with lower air density (Seinfeld and Pandis, 2006). We obtain sedimentation velocity $W_{\text {sed }}$ from

$W_{\text {sed }}=\left(M_{\mathrm{p}} g R_{\mathrm{p}} G\right) /\left(6 \eta A_{2-\mathrm{D}}\right)$,

where $\eta$ is the viscosity of air and $g$ the gravitational constant. For spheres, $W_{\text {sed }}$ is proportional to $R_{\mathrm{p}}^{2}$. For all fractal cases, $R_{\mathrm{p}}$ is taken to be $R_{\mathrm{g}}$, and with $D_{\mathrm{f}} \geq 2$, the area projection is taken to be $\pi R_{\mathrm{g}}^{2}$, yielding a $W_{\text {sed }}$ proportional to $G \times N_{i}^{\left(D_{\mathrm{f}}-1\right) / D_{\mathrm{f}}}$. With $D_{\mathrm{f}}<2$, the fractal is porous and the area projection is $N_{i} \times \pi R_{0}^{2}$, yielding a $W_{\text {sed }}$ proportional to $G \times N_{i}^{\left(1 / D_{\mathrm{f}}\right)}$ (Johnson et al., 1996). For coated particles, the particle mass, $M_{\mathrm{p}}$, is the sum of the solid particle mass and $\mathrm{H}_{2} \mathrm{SO}_{4}-\mathrm{H}_{2} \mathrm{O}$ mass, and particle radius is taken to be $R_{\mathrm{g}}$ increased by the thickness of a uniform coating. However, when the radius of a sphere enclosing the total particle volume is larger than $R_{\mathrm{g}}$ plus a monolayer of $\mathrm{H}_{2} \mathrm{SO}_{4}$, we use the spherical radius rather than $R_{\mathrm{g}}$.

\section{Model results}

Before turning to the results, we use the following subsection to describe (and provide some rationale for) the solid aerosol particles that we choose as test cases, and then in Sect. 3.2 we describe a few results regarding the sedimentation of aggregates that are useful in understanding the model results.

\subsection{Test cases: alumina and diamond aerosol particles}

Several prior studies have examined a range of possible solid aerosols and performed some simple optimizations (Teller et al., 1997; Pope et al., 2012; Blackstock et al., 2009). For simplicity we only considered spherical dielectric particles made of materials that have negligible solubility in the aqueous sulfuric acid found under typical stratospheric conditions. An ideal material for SRM would have (a) a high index of refraction, (b) a relatively low density, (c) negligible absorption for both solar and thermal infrared spectral regions, and finally (d) it should have well-understood surface chemistry under stratospheric conditions. In addition, even though this research is exploratory, materials are more plausible as candidates for deployment for SRM if they have low and well-understood environmental toxicity and if there is a track record of production of industrial quantities of the material in the appropriate half micron size regime.

We chose alumina, or aluminum oxide $\left(\mathrm{Al}_{2} \mathrm{O}_{3}\right)$, as our primary test case because it has a relatively high index of refraction ( $n=1.77$ in the middle of the solar band) and because there is a substantial literature on its chemistry (Molina et al., 1997; Sander et al., 2011) and stratospheric chemical impact (Danilin et al., 2001; Jackman et al., 1998). However, alumina has infrared absorption bands in the thermal infrared that will reduce its net radiative forcing and will cause some heating of the lower stratosphere (Ross and Sheaffer, 2014).

We chose diamond as a secondary test case because of its near-ideal optical properties: it has a very high index $(n=2.4)$ and negligible absorption for both solar and thermal infrared spectral regions. Despite this we did not choose diamond as the primary test case because there are few data about the chemistry of relevant compounds on diamond surfaces under stratospheric conditions, and also, while industrial synthetic submicron diamond is now available at under USD 100 per kilogram, there is still far less industrial heritage on diamond production to assess the challenges of scaling production technologies to hundreds of thousands of tons per year. 
Table 1. Overview of experiments performed with the AER 2-D model.

\begin{tabular}{|c|c|c|c|c|}
\hline $\begin{array}{l}\text { Substance } \\
\text { injected }\end{array}$ & $\begin{array}{l}\text { Injected particle } \\
\text { radius }\end{array}$ & $\begin{array}{l}\text { Injection rate } \\
\left(\operatorname{Tg~yr}^{-1}\right)\end{array}$ & $\begin{array}{l}\text { Fractal dimension } \\
D_{\mathrm{f}}\end{array}$ & Comments \\
\hline Alumina & $R_{0}=80 \mathrm{~nm}^{\mathrm{a}}$ & $1,2,4,8$ & $1.6,2.8$ & \\
\hline Alumina & $R_{0}=160 \mathrm{~nm}^{\mathrm{a}}$ & $1,2,4,8$ & $1.6,2.8$ & \\
\hline Alumina & $R_{0}=240 \mathrm{~nm}^{\mathrm{a}}$ & $1,2,4,8,16$ & $1.6,2.8$ & \\
\hline Alumina & $R_{0}=320 \mathrm{~nm}^{\mathrm{a}}$ & $1,2,4,8$ & $1.6,2.8$ & \\
\hline Diamond & $R_{0}=160 \mathrm{~nm}^{\mathrm{a}}$ & $1,2,4,8$ & 1.6 & \\
\hline $\mathrm{SO}_{2}$ & Gas phase & $1,2,4,10^{\mathrm{c}}$ & & Replication of Pierce et al. (2010) \\
\hline $\mathrm{H}_{2} \mathrm{SO}_{4}$ & $R_{\mathrm{g}}=95 \mathrm{~nm}, \sigma=1.5^{\mathrm{b}}$ & $1,3,6,15^{\mathrm{c}}$ & & Replication of Pierce et al. (2010) \\
\hline
\end{tabular}

Alumina is an important industrial material as a precursor for aluminum production and for a variety of uses, from sunscreen compounds applied to the skin to industrial catalysis. The global production rate is approximately $100 \mathrm{Tg} \mathrm{yr}^{-1}$ (USGS, 2014). There is a very large body of experience in making alumina nanoparticles. For example, liquid-feed flame spray pyrolysis is used to make structured nanoparticles of alumina in quantities greater than $1 \mathrm{kt} \mathrm{yr}^{-1}$ (Hinklin et al., 2004). As we will see, the optimal size for a spherical alumina particles used as a scatterer in the stratosphere is of order $200 \mathrm{~nm}$ radius. Most of the industrial effort is focused on making smaller particles for catalysis but there are examples of production of relatively monodisperse particles with radii greater than $50 \mathrm{~nm}$ (Hinklin et al., 2004; Tsuzuki and McCormick, 2004).

For the purposes of this paper we will assume that it is possible to make roughly spherical alumina particles with a size range between 50 and $400 \mathrm{~nm}$ radius. This is a working assumption that seems plausible based on the very large technical literature ( $>1000$ papers in the last decade on alumina nanoparticles) and industrial base devoted to production of these materials. But it is simply an assumption. A significant effort involving experts from industry and academia would be required to meaningfully assess the difficulty of producing large quantities of alumina with a suitable size and morphology for solar geoengineering.

There is rapidly growing industrial production of submicron diamond powders (Krueger, 2008), so there is no doubt that particles with appropriate morphology can be produced. However, the industrial production volumes and academic literature on production technologies are far smaller than for alumina.

Table 1 lists the numerical experiments performed for this study with the AER 2-D model. Simulations with alumina particles employ a range of injected monomer sizes, from 80 to $320 \mathrm{~nm}$ in radius. These simulations allow us to analyze the trade-offs between sedimentation rate, radiative forcing, and ozone depletion. For diamond, we perform simulations only for injected monomer sizes of $160 \mathrm{~nm}$, near the radiative optimum. We also repeat simulations performed by Pierce et al. (2010) for geoengineering injections of $\mathrm{SO}_{2}$ and $\mathrm{H}_{2} \mathrm{SO}_{4}$. A range of injection rates is used for each injected substance and each injected monomer radius to test linearity of the response. Each scenario is calculated with a 10-year integration period, using dynamical fields representing the 1978-2004 average repeated each year and fixed boundary conditions from approximately the year 2000, until an annually repeating result is achieved. We analyze results from the final year of each calculation, concentrating on annual average conditions.

\subsection{Factors controlling settling of aggregates}

As discussed above, the dynamics of aggregated particles depend on their fractal dimension $D_{\mathrm{f}}$. No observational data on the fractal dimension of $\sim 100 \mathrm{~nm}$ hard spheres aggregating under stratospheric conditions are available. As a guide, we adopt the value of $D_{\mathrm{f}}$ obtained in studies of the formation of fractal alumina aggregates from much smaller monomers at atmospheric pressure produced by combustion and oxidation of liquid aluminum drops that can result from burning solid rocket fuel. These studies, which produced aggregates of approximately $1 \mu \mathrm{m}$ composed of primary particles of a few tens of nanometers in diameter, determined that the fractal dimension $D_{\mathrm{f}}$ for alumina is $1.60 \pm 0.04$ (Karasev et al., 2001, 2004), implying a sparsely packed fractal. For comparison, soot aggregates typically have $D_{\mathrm{f}}$ values of $\sim 2.0$ (Kajino and Kondo, 2011; Maricq and $\mathrm{Nu}, 2004$ ), while a value of 3.0 is appropriate for liquid particles which remain spherical upon coagulation. The density of alumina particles is taken to be $3.8 \mathrm{~g} \mathrm{~cm}^{-3}$ and that of diamond to be $3.5 \mathrm{~g} \mathrm{~cm}^{-3}$. We assume the same fractal dimensions for diamond as for alumina.

Sedimentation velocity strongly influences stratospheric lifetimes. Figure 1a shows annual average sedimentation velocities in the tropics as a function of altitude for uncoated alumina particles for monomer radii from 80 to $320 \mathrm{~nm}$. Sedimentation velocities are shown for individual monomers and for fractals with $N=4$ and $N=32$, all with fractal dimension $D_{\mathrm{f}}=1.6 . N=32$ fractals are not shown for monomers larger than $160 \mathrm{~nm}$ because significant numbers of such frac- 

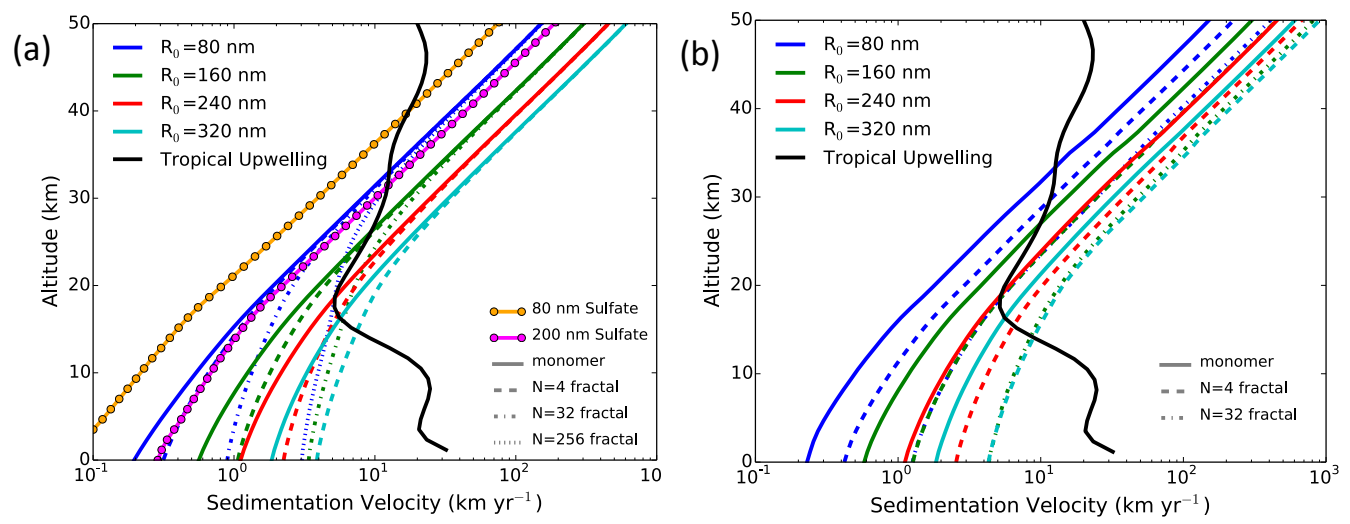

Figure 1. Annual average sedimentation velocity $\left(\mathrm{km} \mathrm{yr}^{-1}\right)$ versus altitude for (a) uncoated alumina particles and pure sulfate particles and (b) sulfate-coated aged alumina paticles with compact fractal structures averaged over the region from $20^{\circ} \mathrm{S}$ to $20^{\circ} \mathrm{N}$ latitude. Solid colored lines represent monomers, dashed lines depict fractals with $N=4$, dash-dot lines depict fractals with $N=32$, and dotted lines depict fractals with $N=256$ (for $R_{0}=80 \mathrm{~nm}$ only). Fractal dimension $D_{\mathrm{f}}=1.6$ for uncoated particles represented in panel (a), $D_{\mathrm{f}}=2.8$ for coated and compacted particles shown in panel (b). The black lines represent the annual average upwelling velocity of the model's advective transport averaged over the region from $20^{\circ} \mathrm{S}$ to $20^{\circ} \mathrm{N}$ latitude for comparison.

tals do not form in our simulations, however we do show $N=256$ fractals with $80 \mathrm{~nm}$ monomers. Alumina monomers fall at a faster rate than sulfate particles of the same diameter, given their greater density $\left(3.8 \mathrm{~g} \mathrm{~cm}^{-3}\right.$ for $\mathrm{Al}_{2} \mathrm{O}_{3}$, approximately $1.7 \mathrm{~g} \mathrm{~cm}^{-3}$ for stratospheric $\mathrm{H}_{2} \mathrm{SO}_{4}-\mathrm{H}_{2} \mathrm{O}$ particles), and diamond particles (not shown) fall only slightly slower than alumina particles of the same radius owing to $8 \%$ smaller density. Fractal particles fall faster than the monomers they are composed of in the troposphere and lower stratosphere, but at the same rate in the middle and upper stratosphere where the Knudsen number $K n>1$ and the slipflow correction have the opposite size dependence as the other terms. Figure 1 also shows the model's average upward advective velocity in the tropics as a function of altitude for comparison. Where sedimentation velocity exceeds average upwelling velocity, we expect alumina lifetime and vertical extent to be greatly impacted. This occurs only above $30 \mathrm{~km}$ for $80 \mathrm{~nm}$ monomers, but above $24 \mathrm{~km}$ for $160 \mathrm{~nm}$ monomers and $19 \mathrm{~km}$ for $240 \mathrm{~nm}$ monomers. For 240 and $320 \mathrm{~nm}$ monomers injected into the tropics at $20-25 \mathrm{~km}$ altitude, only a fraction of the injected mass will be lofted to higher altitudes and distributed to high latitudes by the Brewer-Dobson circulation.

It is known that soot particles, which form fractals similar to alumina particles, eventually assume a more compact structure in the atmosphere after acquiring a liquid coating (Kajino and Kondo, 2011; Mikhailov et al., 2006). Observations on the liquid uptake properties of alumina and their potential shape compaction are not available. For simplicity, we assume that the alumina particles are hydrophobic until they are coated with a sulfate-water mixture by coagulation with existing sulfate particles, and then they may take up additional $\mathrm{H}_{2} \mathrm{SO}_{4}$ and $\mathrm{H}_{2} \mathrm{O}$ by condensation. The effects of this assumption are expected be small under nonvolcanic condi- tions, as most ( $>95 \%)$ stratospheric sulfate mass exists in condensed form. To test the potential effect of compaction of liquid-coated solid alumina particles, we perform additional model calculations, assuming that the wetted particles change their fractal dimension $D_{\mathrm{f}}$ from 1.6 to 2.8 , and their surface area scaling exponent $D_{h}$ from 2.0 to 2.8 , likely the maximum compaction that could be achieved. While a time lag from initial wetting to shape compaction may be appropriate, we assume instantaneous compaction on wetting for calculations labeled "compact coated" as a way to bracket the effect. When the compacted particles lose their $\mathrm{H}_{2} \mathrm{SO}_{4}$ by evaporation, they are assumed to retain their compact shape. Sedimentation velocities for these coated and compacted particles are shown in Fig. 1b. In this case, higher-order fractals fall at faster velocities than their respective monomers at all altitudes, which will affect the residence time of alumina and its calculated atmospheric burden.

\subsection{Aerosol distribution and burden}

We model geoengineering by injection of alumina particles for a number of parametric model scenarios to evaluate the effect of (1) injected particles size, (2) injection rate, and (3) the fractal geometry of sulfate-coated alumina particles. For all scenarios, injection occurs in a broad band from $30^{\circ} \mathrm{S}$ to $30^{\circ} \mathrm{N}$ and from 20 to $25 \mathrm{~km}$ in altitude. This is the same injection region used in Pierce et al. (2010) and was chosen to maximize the global distribution and residence time of geoengineered aerosols while minimizing localized injection overlaps. We assume that it is feasible to emit alumina particle monomers with a uniform diameter, either by a flame process at the injection nozzle or by releasing prefabricated particles. Particles are released continuously at injection rates of $1,2,4$, or $8 \mathrm{Tg}$ per year, all as monomers of a single ra- 

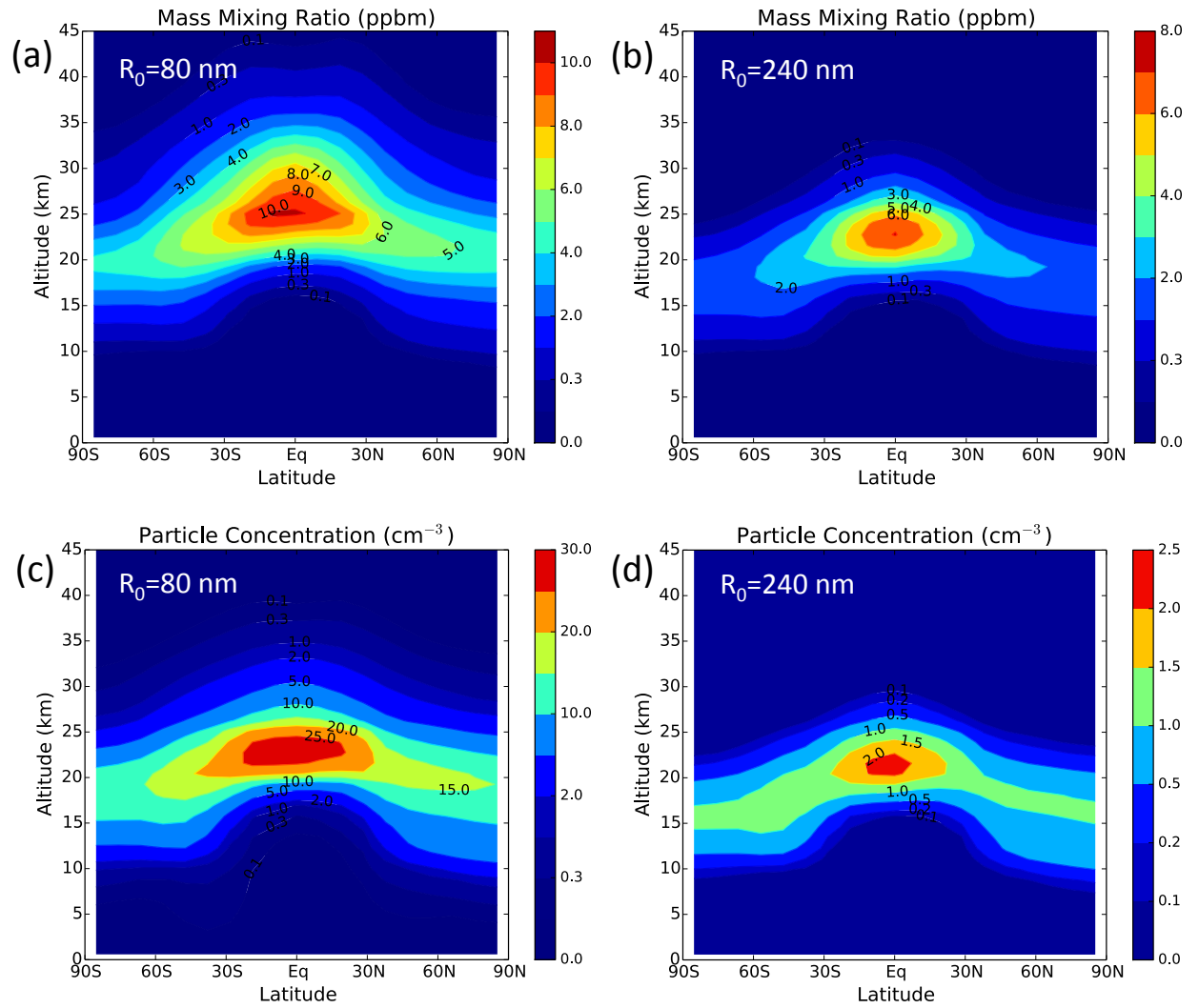

Figure 2. Mass mixing ratio of alumina in ppbm (panels $\mathbf{a}$ and $\mathbf{b}$ ) and number density of alumina particles in $\mathrm{cm}^{-3}$ (panels $\mathbf{c}$ and $\mathbf{d}$ ) with geoengineering injections of $1 \mathrm{Tg} \mathrm{yr}^{-1}$ of $80 \mathrm{~nm}$ monomers (panels a and $\mathbf{c}$ ) and $1 \mathrm{Tg} \mathrm{yr}^{-1}$ of $240 \mathrm{~nm}$ monomers (panels $\mathbf{b}$ and $\mathbf{d}$ ) for annual average conditions.

dius $(80,160,240$, or $320 \mathrm{~nm})$, as detailed in Table 1 . Stratospheric particle injections are continuous in time and the simulations are continued for 10 years until a steady atmospheric concentration is reached. Alumina particles that become coated with sulfate are treated either as retaining their sparse structure with fractal dimension $D_{\mathrm{f}}$ of 1.6 or instantaneously becoming more compact fractal particles with $D_{\mathrm{f}}$ of 2.8. We use a 2-D model for computation efficiency in this first evaluation of geoengineering by solid particle injection, and thus we implicitly mix the injected material into zonally uniform bands dictated by the model's spatial resolution of $9.5^{\circ}$ latitude by $1.2 \mathrm{~km}$ altitude. The impact of this simplification, along with the neglect of enhanced coagulation in injection plumes, will be discussed in Sect. 4 .

We first examine the calculated concentration and size distribution of atmospheric alumina under a geoengineering scenario with an injection rate of $1 \mathrm{Tg} \mathrm{yr}^{-1}$, assuming no particle compaction on coating with sulfate. Figure 2, top panels, shows the mass mixing ratio of alumina (ppbm) with injections of $80 \mathrm{~nm}$ monomers and $240 \mathrm{~nm}$ monomers. Significant alumina concentration exist up to $40 \mathrm{~km}$ altitude when $80 \mathrm{~nm}$ particles are injected, but only below $30 \mathrm{~km}$ for the injection of $240 \mathrm{~nm}$ particles due to the difference in sedimentation speeds. The peak mass mixing ratio of alumina injected with $80 \mathrm{~nm}$ monomers is $40 \%$ larger than that injected with $240 \mathrm{~nm}$ monomers. The lower panels of Fig. 2 show the concentration of particles $\left(\mathrm{cm}^{-3}\right)$ for the same cases. Particle concentrations of up to $25 \mathrm{~cm}^{-3}$ are found for $1 \mathrm{Tg} \mathrm{yr}^{-1}$ injection of $80 \mathrm{~nm}$ monomers but remain less than $3 \mathrm{~cm}^{-3}$ for the injection of $240 \mathrm{~nm}$ monomers. The particle concentration drops away from the injection region as the monomers coagulate into fractals and have time to settle downward. The low number densities with $R_{0}=240 \mathrm{~nm}$ result in minimal coagulation between alumina particles.

The distribution of stratospheric alumina mass into monomers and fractals is shown in Fig. 3 at the equator with $80 \mathrm{~nm}$ monomers injected (panel a) and for the global average injected with 80,160 , and $240 \mathrm{~nm}$ monomers (panels $\mathrm{b}-\mathrm{d})$, all with $1 \mathrm{Tg} \mathrm{yr}^{-1}$ of emissions. With the injection of $80 \mathrm{~nm}$ monomers, $27 \%$ of the mass remains in monomers at the equator, with no more than $13 \%$ of the mass in any size bin with two or more monomers in the fractal. Some fractal particles comprised of 1024 monomers exist. At higher latitudes, the monomer fraction drops and the proportion in higher-order fractals increases, as seen in the global average (panel $b$ ). The fraction of coated monomers, shown as the blue portion of each bar, increases with distance from the tropical injection region. Coated fractions also increase 
(a)

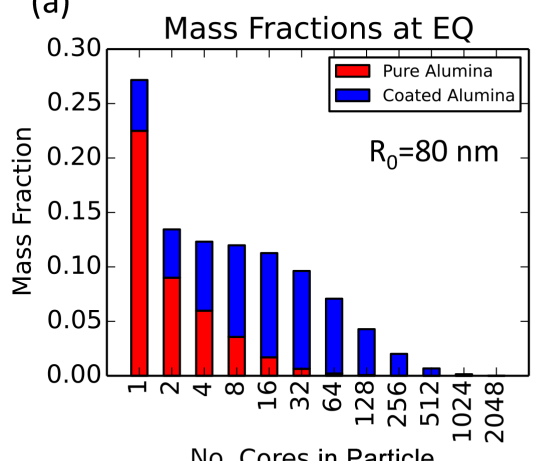

No. Cores in Particle

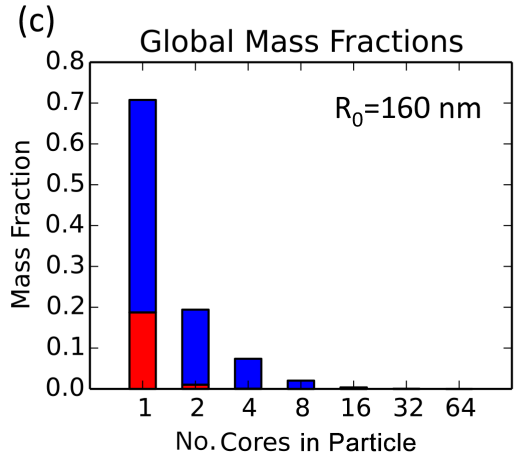

(b)

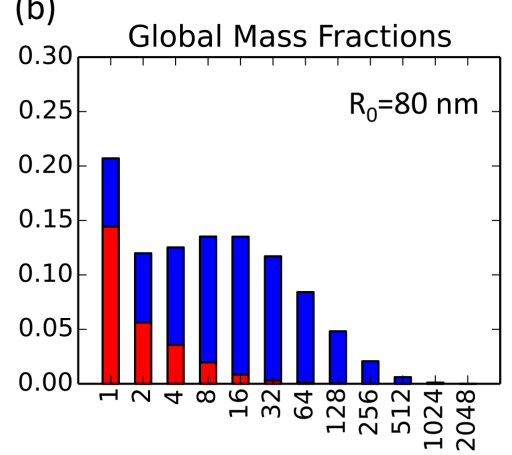

No. Cores in Particle

(d)

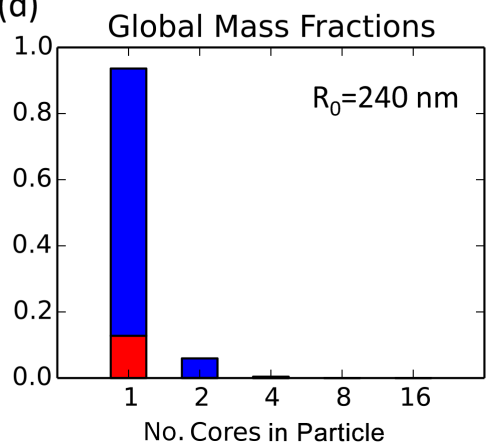

Figure 3. Distribution of integrated stratospheric alumina mass into monomers and fractals for geoengineering injection of $1 \mathrm{Tg}^{-1} \mathrm{of}^{-1}$ alumina as $80 \mathrm{~nm}$ monomers at (a) the equator and (b), globally integrated, and for injection of $1 \mathrm{Tg} \mathrm{yr}^{-1}$ of alumina as (c) $160 \mathrm{~nm}$ and (d) $240 \mathrm{~nm}$ monomers, globally integrated. Red bar length represents the mass fraction in dry alumina and blue bar length the mass fraction in coated alumina. Annual average conditions are represented.
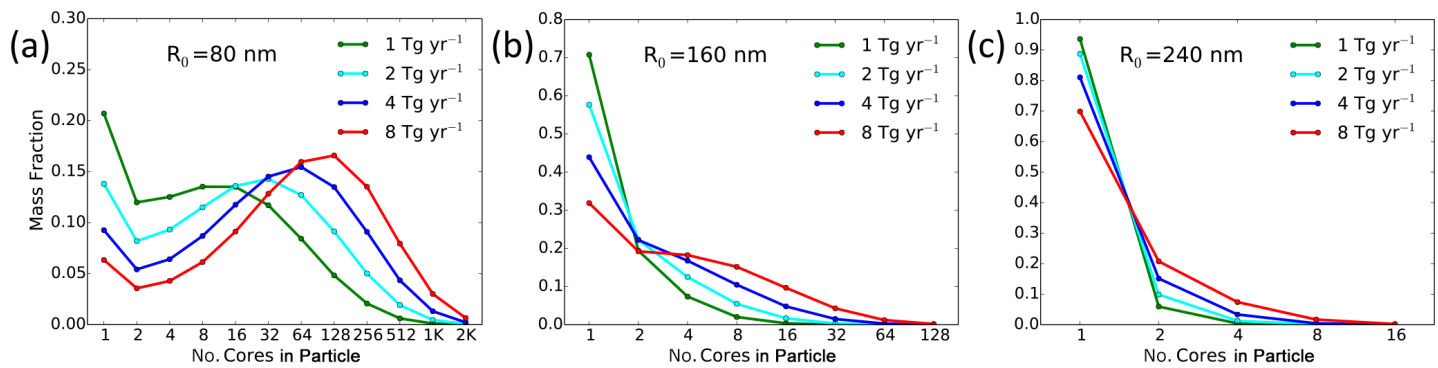

Figure 4. Calculated global annual average stratospheric mass fractions of alumina as a function of the number of monomers contained in a fractal particle for (a) monomer injections of $80 \mathrm{~nm}$ radius, (b) monomer injections of $160 \mathrm{~nm}$, and (c) monomer injections of $240 \mathrm{~nm}$ radius, with emission rates ranging from 1 to $8 \mathrm{Tg} \mathrm{yr}^{-1}$.

with increasing numbers of monomers per fractal particle. This reflects both the longer residence time of the larger particles and their large cross section, which enhances coagulation with sulfate particles. Virtually all of the alumina mass is coated for fractals with more than 128 monomers per particle. Alumina in the troposphere is almost all coated with sulfate due to the large sulfate concentrations there, though alumina concentrations are small. With the injection of $160 \mathrm{~nm}$ alumina monomers, $71 \%$ of the global mass remains in monomers, and fractals composed of only 2-16 monomers are found in significant concentrations. Results for diamond closely resemble those for alumina injected with $160 \mathrm{~nm}$ monomers. With the injection of $240 \mathrm{~nm}$ alumina monomers, $94 \%$ of the mass remains in monomers, and with $320 \mathrm{~nm}$ monomers injected, $98 \%$ remains in monomers. Larger fractions of the alumina mass are coated in these latter cases.

The mass fraction in monomers versus higher-order fractals varies with injection rate. Figure 4 shows mass fraction vs the number of monomers per particle for injection of $80 \mathrm{~nm}$ monomers at rates varying from 1 to $8 \mathrm{Tg} \mathrm{yr}^{-1}$. The $1 \mathrm{Tg} \mathrm{yr}^{-1}$ cases (green lines) match the global mass fractions 
shown in Fig. 3. As the injection rate increases, the mass fraction of monomers decreases while the peak distribution shifts to larger fractals. At injection rates of 2,4 , and $8 \mathrm{Tg} \mathrm{yr}^{-1}$, the size distribution peaks at 32, 64, and then 128 monomers per particle, and fractals composed of 2000 monomers are found. Figure $4 \mathrm{~b}$ shows a similar figure with injection of alumina as $160 \mathrm{~nm}$ radius monomers. Because these particles contain 8 times the mass of the $80 \mathrm{~nm}$ monomers, particle concentrations are considerably smaller and coagulation is less effective. Fractals containing more than 128 monomers do not occur in significant concentrations, even with $8 \mathrm{Tg} \mathrm{yr}^{-1}$ of emission. For injection of $240 \mathrm{~nm}$ monomers (Fig. 4c), $70 \%$ of the particles remain as monomers even with $8 \mathrm{Tg} \mathrm{yr}^{-1}$ of emission, and fractals exceeding 16 monomers exist at only insignificant concentrations. For the injection of $320 \mathrm{~nm}$ monomers (not shown), significant concentrations are found only for monomers and fractals composed of two and four monomers even with $8 \mathrm{Tg} \mathrm{yr}^{-1}$ of emission.

Figure 5a shows the stratospheric alumina burden as a function of injection rate for four different radii of injected monomers. Alumina burden is seen to be approximately linear with injection rate. This is in contrast to a more strongly decreasing rate of change with increasing injection rate seen for geoengineering by injection of $\mathrm{SO}_{2}$ or $\mathrm{H}_{2} \mathrm{SO}_{4}$, also shown in Fig. 5a. In the case of sulfur injection, particles that grow to larger spherical sizes have shorter atmospheric residence times. For alumina particles with sparse fractal structure $\left(D_{\mathrm{f}}=1.6\right)$, the fractal particles do not increase their sedimentation velocities in the middle and upper stratosphere as they grow by coagulation, resulting in residence times remaining almost constant over the alumina size distribution. The cases that produce the fewest fractals ( $R_{0}=240$ and $320 \mathrm{~nm}$ ) have the most linear response. The calculated atmospheric burden for diamond (not shown) is almost identical to that for alumina of the same size injected monomer. Also shown in Fig. 5 as dashed lines are simulations with coated alumina particles assumed to adopt a more compact fractal shape $\left(D_{\mathrm{f}}=2.8\right)$. For these scenarios, total stratospheric burden is reduced due to the faster sedimentation of the coated fractal particles, while the mass fraction in monomers is increased due to fewer high-order fractals to scavenge the monomers. Only the 80 and $160 \mathrm{~nm}$ cases show significant differences under the assumption that coated particles become more compact.

The stratospheric burden of sulfate is shown in Fig. 5b under various geoengineering scenarios with alumina injection. Thick lines (left-hand axis labels) represent the total stratospheric burden of condensed sulfate as a function of geoengineering injection rate of alumina while thin lines (righthand axis labels) represent the fraction of stratospheric liquid sulfate on the surface of alumina particles. With injection of $80 \mathrm{~nm}$ alumina monomers, total stratospheric sulfate increases above background for injections less than $1.5 \mathrm{Tg} \mathrm{yr}^{-1}$, but then decreases with higher injection rates. Up to $86 \%$ of the total stratospheric sulfate is found on alumina particles in these cases, a result of the large alumina surface area available and high coagulation rates with large fractals. Alumina injection cases with larger monomer diameters lead to decreases in the total stratospheric burden of liquid sulfate because of the faster sedimentation of the larger alumina particles along with their sulfate coatings. The maximum decrease in total stratospheric sulfate is about $30 \%$. The fraction of total stratospheric sulfate found on alumina particles is as much as $82 \%$ with $160 \mathrm{~nm}$ monomers, $61 \%$ with $240 \mathrm{~nm}$ monomers, and $32 \%$ with $320 \mathrm{~nm}$ monomers. The calculated thickness of the sulfate coating on alumina particles in the stratosphere varies from 5 to $15 \mathrm{~nm}$ with $80 \mathrm{~nm}$ monomers and from 10 to $40 \mathrm{~nm}$ with $240 \mathrm{~nm}$ monomers with $1 \mathrm{Tg} \mathrm{yr}^{-1}$ of injection. However, as the geoengineering injection rate increases, the sulfate layer on alumina particles becomes thinner since the stratospheric sulfate burden will then be distributed over a larger alumina surface area.

\subsection{Radiative forcing assessment}

In this work, we confine our assessment of radiative forcing (RF) to reflected solar radiation, acknowledging that absorption of thermal infrared radiation generates a longwave radiative forcing as well. For some materials, this longwave forcing can be significant, reaching approximately $20 \%$ of the shortwave radiative forcing in the case of sulfate. Compared to the shortwave forcing, however, the longwave forcing is a much more sensitive function of profiles of atmospheric temperature, humidity, ozone, and well-mixed greenhouse gases. Furthermore, the instantaneous longwave forcing adjusts in response to changes in the temperature profile caused by radiative heating rate perturbations due to the aerosol particles. We therefore restrict our analysis to shortwave radiative forcing to narrow the scope of radiative transfer calculations and to reduce the number of radiative forcing values presented.

Alumina particles are known to be more efficient scatterers than sulfate particles, and thus are expected to be more efficient per unit mass for geoengineering applications. Figure 6 compares the Mie scattering properties in the solar band of alumina and diamond monomers and sulfate particles as a function of particle radius. We calculated the solid particle monodisperse single scatter albedo values from Mie theory (Bohren and Huffman, 2008) using tabulated complex refractive index data for diamond (Edwards and Philipp, 1985) and alumina (Thomas and Tropf, 1997). The upscatter and downscatter cross sections are calculated from Wiscombe and Grams (1976), utilizing the scattering-phase function from Mie theory and the same complex refractive index data. Figure 6a shows the ratio of upscatter cross section to geometric cross section for the three particle types. The sulfate profile is fairly flat, with a cross section of about 0.3 for particles greater than $0.5 \mu \mathrm{m}$, whereas the alumina profile shows a $30 \%$ drop from its peak of 0.6 between 0.2 and $0.6 \mu \mathrm{m}$ to 0.4 at $2 \mu \mathrm{m}$. The diamond profile shows a peak of 0.9 between 

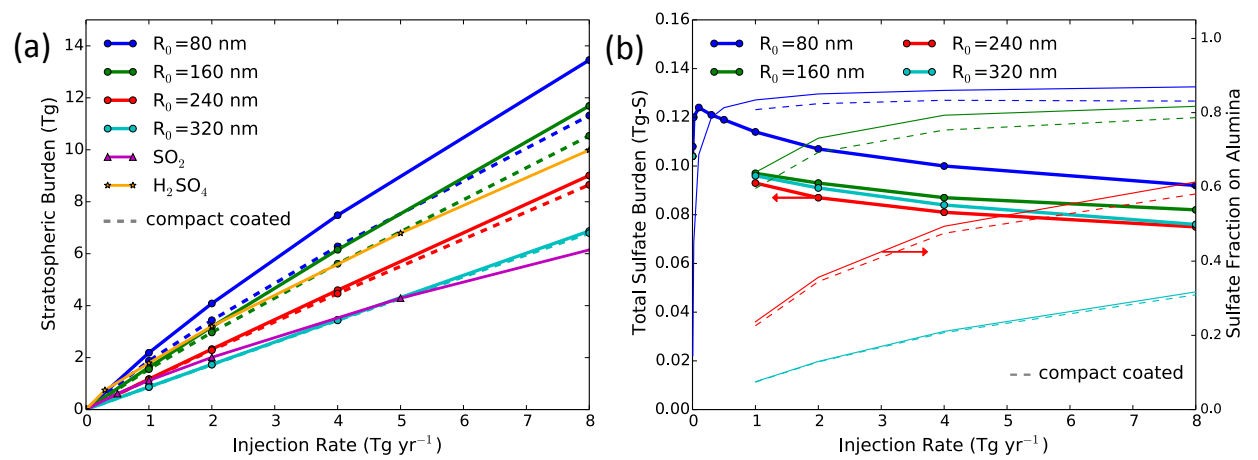

Figure 5. Annual average stratospheric burden of (a) alumina and (b) condensed sulfate versus injection rate for various sizes of injected alumina monomers. For comparison, we plot sulfate burden in Tg-S as a function of the rate of injection of $\mathrm{SO}_{2}$ and $\mathrm{H}_{2} \mathrm{SO}_{4}(\mathrm{Pierce}$ et al., 2010) in $\mathrm{Tg}_{-} \mathrm{S} \mathrm{yr}^{-1}$ along with alumina burden in (a). Panel (b) shows the fate of natural sulfate as a function of alumina injection rate, where the total sulfate burden is plotted on the left-hand axis (thick lines with circles) and the fraction of that burden that is on the alumina particles is shown on the right-hand axis (thin lines). The dashed lines represent simulations in which the coated alumina particles are assumed to become more compact in shape.

0.15 and $0.5 \mu \mathrm{m}$, dropping to about 0.55 at radii greater than $1.2 \mu \mathrm{m}$. Figure $6 \mathrm{~b}$ shows strong peaks in upscatter per unit volume for alumina and diamond monomers as a function of radius. In contrast, sulfate particles exhibit a much flatter function of upscatter per unit volume as a function of radius. Alumina monomers scatter most efficiently per unit particle volume at about $200-250 \mathrm{~nm}$. At this radius, they have 3 times the upscatter per unit volume as sulfate particles. Upscatter per unit mass however, due to the difference in density of alumina relative to sulfate, shows less contrast. For diamond monomers, the upscatter per unit volume peaks at around $150 \mathrm{~nm}$ radius, with over twice the peak upscatter of alumina monomers. Figure $6 \mathrm{c}$ shows the ratio of downscatter cross section to upscatter cross section for alumina, diamond, and sulfate as a function of radius. Alumina monomers have about half the downscatter per unit of upscatter as sulfate particles, while diamond monomers have half the downscatter of alumina. Thus in geoengineering applications, alumina and diamond would scatter radiation back to space and produce substantially smaller increases in diffuse radiation at the surface than sulfate particles producing the same change in RF would.

We use a scattering code which integrates the Mie scattering function over shortwave spectral bands and scattering angles as a function of particle size (monomers and fractals) using an efficient impulse-function method. Multiple scattering is ignored as solid particle optical depths are small. For purposes of radiative forcing, we assume that solid particles with thin sulfate coatings behave the same as bare particles. We follow Rannou et al. (1999) for scattering by fractals, and follow the approximation in Charlson et al. (1991) by scaling our calculated RF values by $(1-\alpha)^{2}$, where $\alpha$ represents surface albedo, here taken to be 0.2 . Figure 7a shows the shortwave globally averaged clear-sky radiative forcing functions, in $\mathrm{W} \mathrm{m}^{-2}$ per $\mathrm{Tg}$ of aerosol burden, obtained by our scatter- ing code as a function of monomer radius and fractal size (number of cores per particle). Scattering by $80 \mathrm{~nm}$ alumina monomers is much less efficient (factor of 4) than scattering by $160 \mathrm{~nm}$ alumina monomers. There is little difference in scattering between 240 and $320 \mathrm{~nm}$ alumina monomers, both with about $50 \%$ greater RF per teragram burden than $160 \mathrm{~nm}$ monomers. Fractals scatter much less efficiently than monomers. A fractal aggregate of two cores scatters only $50 \%$ as much radiation per unit mass as a corresponding monomer, and higher-order fractals scatter even less efficiently. An aggregate of 16 alumina monomers has negligible scattering per unit mass. The functions with fractal dimension of both $D_{\mathrm{f}}=1.6$ (solid lines) and $D_{\mathrm{f}}=2.8$ (dashed lines, labeled "compact coated") are shown for alumina, however, this produces only a minor difference in radiative forcing per unit mass. The radiative forcing function for diamond with $160 \mathrm{~nm}$ monomers (the radius of peak backscatter efficiency) shows significantly greater forcing than alumina, 2.7 times greater than $160 \mathrm{~nm}$ alumina monomers and 1.8 times greater than $240 \mathrm{~nm}$ alumina monomers.

We obtain averages of solid aerosol mass in each bin size (monomers and fractals) integrated vertically and averaged over latitude and season. The integrated and averaged aerosol mass per bin is multiplied by the spectrally integrated radiative forcing per teragram burden for each bin to obtain the total radiative forcing for each geoengineering scenario. The global annual average top-of-atmosphere shortwave radiative forcing due to alumina and diamond is shown in Fig. $7 \mathrm{~b}$ as a function of injection rate for specified sizes of injected monomers under clear-sky conditions. As stated at the beginning of this section, our analysis focuses on shortwave radiative forcing, as it provides for a less ambiguous comparison, relative to combined shortwave plus longwave forcing, of the efficacy of different particles in offsetting surface warming. However, we note that the longwave radiative forc- 
(a)

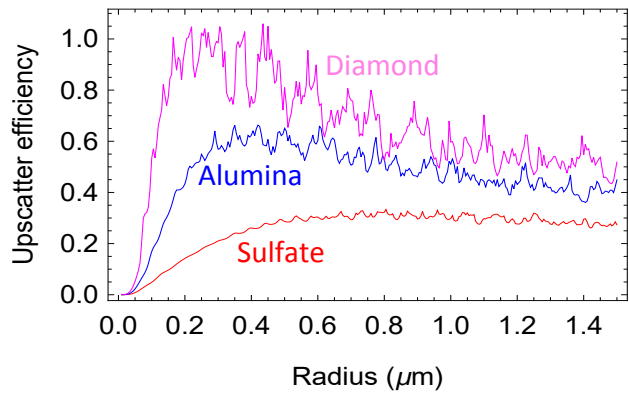

(b)

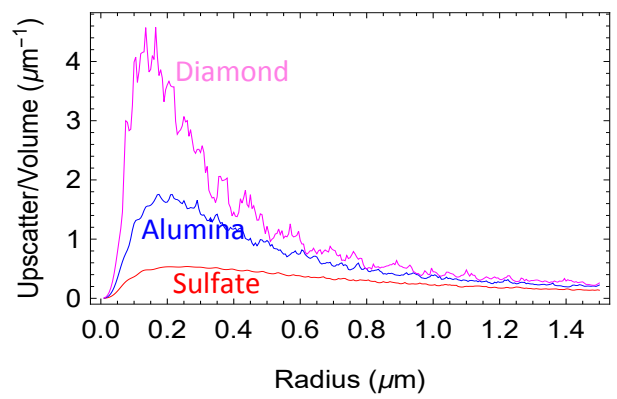

(c)

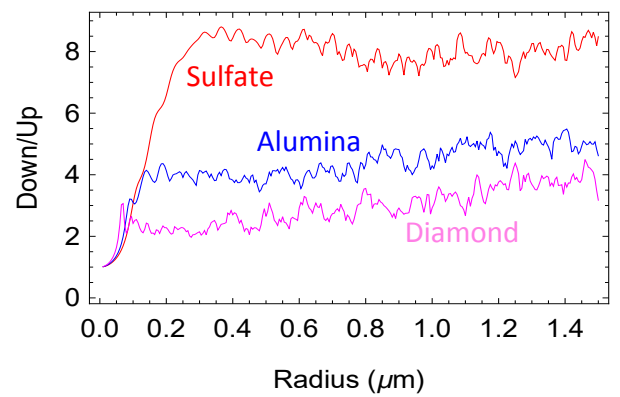

Figure 6. Comparison of radiative scattering properties of alumina and diamond monomers and sulfate aerosol particles as functions of particle radius. Panel (a) shows the upscatter efficiency which is the upscatter cross section divided by the geometric cross section (a dimensionless ratio). Panel (b) shows the upscatter cross section divided by the particle volume (units of $\mu \mathrm{m}^{-1}$ ), and panel (c) shows the ratio of downscatter cross section to upscatter cross section integrated over the solar band.

ing is about $10 \%$ of the shortwave RF for alumina, though of opposite sign, and is negligible for diamond.

For alumina, shortwave RF for cases with 80, 160, 240, and $320 \mathrm{~nm}$ injected monomer size are shown in Fig. $7 \mathrm{~b}$ as a function of injection rate. Cases with $80 \mathrm{~nm}$ monomer injections have very low RF, due both to inefficient scattering for monomers of that size, and the large proportion of fractals to monomers. The RF for the $80 \mathrm{~nm}$ injection case increases very little with increasing injection rate, as increasing injections produce fractals composed of more than 64 monomers which produce almost no scattering per unit mass. The case with injection of $320 \mathrm{~nm}$ alumina monomers produces less RF than the case with the injection of $240 \mathrm{~nm}$ alumina monomers. Though monomers of $320 \mathrm{~nm}$ produce slightly more RF per teragram than monomers of $240 \mathrm{~nm}$, the $320 \mathrm{~nm}$ injection cases yield a smaller burden due to their faster sedimentation rates. The injection of $240 \mathrm{~nm}$ monomers is found to produce the most radiative forcing per teragram of alumina injected annually, consistent with the peak of the upscatter per unit volume curve shown in Fig. 6b. We calculate radiative forcing for diamond injections of $160 \mathrm{~nm}$ monomers only, also shown in Fig. 7b. Atmospheric burden of diamond is very similar to that for alumina of the same radius, but $\mathrm{RF}$ is much larger owing to more efficient scattering. Diamond injection at a rate of $4 \mathrm{Tg} \mathrm{yr}^{-1}$ results in $-1.8 \mathrm{~W} \mathrm{~m}^{-2}$ of shortwave forcing, while the same alumina injection results in only $-1.2 \mathrm{~W} \mathrm{~m}^{-2}$ of shortwave forcing. The increase in downward diffusive flux is also calculated by our radiative forcing code and is shown in Table 2 for selected cases which each produce $-2 \mathrm{~W} \mathrm{~m}^{-2}$ of shortwave radiative forcing. For equivalent radii and injection rate, diamond produces up to twice the diffuse downward radiation as alumina, however, per unit change in top-of-atmosphere shortwave radiative forcing, diamond produces less diffuse downward radiation.

Our method produces only a globally averaged value of shortwave radiative forcing by solid particles. Our results are not meant to be of high accuracy, as they do not account for clouds or molecular scattering and are limited by the index of refraction data, uncertainties in fractal scattering, and our averaging method. Nevertheless, it is useful to obtain wellfounded estimates of radiative forcing for comparison with sulfate geoengineering, and relative efficiencies among solid particle scenarios as a function of injected monomer diameter. The RF plot in Fig. 7b shows clear-sky shortwave radiative forcing from two sulfur geoengineering scenarios as well. The scenario results were calculated with the AER 2-D model, as applied in Pierce et al. (2010) but using the radiative scattering code applied to alumina and diamond. Note that we plot them here relative to the total $\mathrm{SO}_{2}$ or $\mathrm{H}_{2} \mathrm{SO}_{4}$ injection mass per year, not the sulfur mass injected per year. The most efficient alumina geoengineering scenario, with $240 \mathrm{~nm}$ monomers injected, has roughly the same RF efficiency per teragram of injection as geoengineering by the injection of $\mathrm{H}_{2} \mathrm{SO}_{4}$. However, if a geoengineering methodology were to transport only sulfur to the stratosphere and create $\mathrm{H}_{2} \mathrm{SO}_{4}$ in situ, then sulfur geoengineering would be more efficient than alumina per teragram per year transported.

Aerosol heating of the tropical lower stratosphere is another potential risk of geoengineering. Heckendorn et al. (2009) investigated this effect and the resulting increase in stratospheric water vapor, primarily caused by longwave heating, for sulfate aerosol. To estimate lower stratospheric heating by solid particles, we use the Rapid Radiative Transfer Model (RRTM) developed by Atmospheric and Environmental Research (Mlawer et al., 1997; Clough et al., 2005) to calculate radiative heating rates for mean cloud-free tropical atmospheric profiles with and without a uniform aerosol density of $1 \mathrm{~cm}^{-3}$ between 18 and $23 \mathrm{~km}$. The combined longwave and shortwave heating rates shown in Table 2 for 

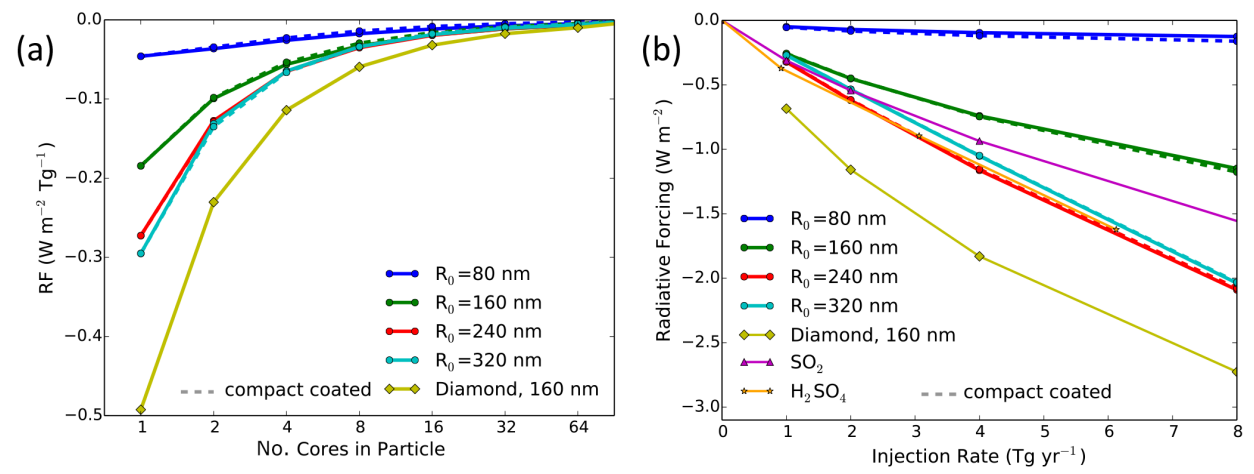

Figure 7. Shortwave globally averaged clear-sky radiative forcing per teragram burden $\left(\mathrm{W} \mathrm{m}^{-2} \mathrm{Tg}^{-1}\right)$ of alumina or diamond particles as a function of the number of monomer cores per fractal particle (panel a). Calculated globally averaged shortwave radiative forcing as a function of injection rate for geoengineering scenarios (panel b) for annual average cloud-free conditions. The dashed lines represent simulations in which the coated alumina particles are assumed to become more compact in shape.
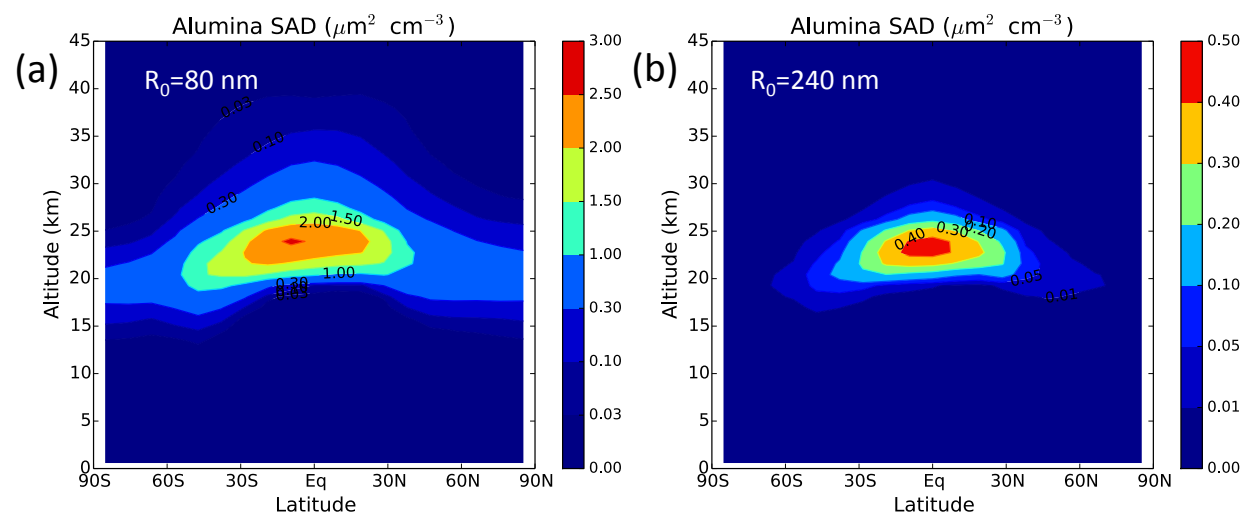

Figure 8. Calculated annual average surface area density $\left(\mu \mathrm{m}^{2} \mathrm{~cm}^{-3}\right)$ of uncoated alumina particles due to geoengineering with $1 \mathrm{Tg}$ yr ${ }^{-1}$ injection of (a) $80 \mathrm{~nm}$ alumina monomers and (b) $240 \mathrm{~nm}$ alumina monomers.

alumina, diamond, and sulfate are generated by scaling the RRTM results for number densities of $1 \mathrm{~cm}^{-3}$ to the average number density in the $18-23 \mathrm{~km}$ region between $30^{\circ} \mathrm{S}$ and $30^{\circ} \mathrm{N}$ for scenarios predicted to produce $-2 \mathrm{~W} \mathrm{~m}^{-2}$ of shortwave radiative forcing. For alumina and diamond, the RRTM calculation uses only the monomer size of 240 or $160 \mathrm{~nm}$, respectively, ignoring fractal particles and treating coated monomers the same as uncoated monomers. The range provided for heating by alumina and diamond in Table 2 uses monomer number densities for the low estimate and total particle number densities for the high estimate as multipliers for the heating rate determined from RRTM with average number density of $1 \mathrm{~cm}^{-3}$. For sulfate particles, we employ a size distribution due to the sensitivity of heating rates to particle diameter and the range of diameters generated in geoengineering scenarios. We find that the lower stratospheric heating rate from alumina is approximately 4-5 times less than the heating rate from sulfate, comparing scenarios which each generate $-2 \mathrm{~W} \mathrm{~m}^{-2}$ of shortwave RF. Shortwave heating from alumina is about $15 \%$ of the total heating by gases and aerosols, and from sulfate about $20 \%$. The total heating rate from diamond is almost entirely due to shortwave effects, but is still much less than that for alumina with the same top-of-atmosphere shortwave radiative forcing.

\subsection{Ozone impacts}

Heterogeneous reactions on stratospheric particles play an important role in ozone chemistry by converting inactive forms of chlorine and bromine to forms that contribute directly to catalytic destruction of ozone. In addition, the heterogeneous conversion of $\mathrm{N}_{2} \mathrm{O}_{5}$ to $\mathrm{HNO}_{3}$ reduces $\mathrm{NO}_{x}$ concentrations. This increases ozone concentrations in the middle stratosphere where $\mathrm{NO}_{x}$ reactions dominate the ozone loss cycles, but it decreases ozone concentrations in the lower stratosphere where $\mathrm{HO}_{x}, \mathrm{ClO}_{x}$, and $\mathrm{BrO}_{x}$ loss cycles dominate. Transient increases in sulfate aerosols following volcanic eruptions have caused temporary depletions in ozone (Solomon, 1999). Geoengineering by stratospheric aerosol injection would be expected to lead to analogous ozone depletion, depending on the heterogeneous reactions that occur on the particle surfaces and their rates. 
Table 2. Comparison of alumina, diamond, and sulfate solar geoengineering, based on a top-of-atmosphere shortwave radiative forcing of $-2 \mathrm{~W} \mathrm{~m}^{-2}$ for each case.

\begin{tabular}{|c|c|c|c|c|c|}
\hline Metric & Alumina $240 \mathrm{~nm}$ & Diamond $160 \mathrm{~nm}$ & Sulfate as $\mathrm{H}_{2} \mathrm{SO}_{4}$ & Sulfate as $\mathrm{SO}_{2}$ & Comments \\
\hline $\begin{array}{l}\text { Shortwave radiative forcing per } \\
\text { unit injected mass flux } \\
\left(\mathrm{W} \mathrm{m}^{-2}\left(\mathrm{Tg} \mathrm{yr}^{-1}\right)^{-1}\right)\end{array}$ & -0.26 & -0.42 & $-0.25^{\mathrm{a}}$ & $-0.20^{\mathrm{a}}$ & $\begin{array}{l}\text { Other than diamond, the differences are } \\
\text { minor. }\end{array}$ \\
\hline $\begin{array}{l}\text { Ozone impact (global average } \\
\text { column change) }\end{array}$ & $-5.6 \%$ & $-6.1 \%$ to $-7.1 \% \mathrm{~b}$ & $-13 \% \mathrm{c}$ & $-11 \% \mathrm{c}$ & $\begin{array}{l}\text { Alumina and diamond have less ozone } \\
\text { depletion than sulfates, though there is } \\
\text { considerable uncertainty. }\end{array}$ \\
\hline $\begin{array}{l}\text { Diffuse light increase } \\
\left(\mathrm{W} \mathrm{m}^{-2}\right)\end{array}$ & 10.1 & 6.3 & 21 & 19 & $\begin{array}{l}\text { Alumina and diamond are both better } \\
\text { (less diffuse light) than sulfates. Exact } \\
\text { results would require a more sophisti- } \\
\text { cated radiative transfer model. }\end{array}$ \\
\hline $\begin{array}{l}\text { Longwave and shortwave heat- } \\
\text { ing rate }\left(\mathrm{K} \mathrm{day}^{-1}\right) \text { in tropical } \\
\text { lower stratosphere }\end{array}$ & $0.052-0.060^{\mathrm{d}}$ & $0.007-0.010^{\mathrm{d}}$ & 0.22 & 0.30 & $\begin{array}{l}\text { Alumina is probably better (less heat- } \\
\text { ing) than sulfates, but this estimate is } \\
\text { subject to considerable uncertainty. Di- } \\
\text { amond is much better. }\end{array}$ \\
\hline
\end{tabular}

Ozone loss due to geoengineering injections of sulfate precursors has been explored by several authors (Heckendorn et al., 2009; Tilmes et al., 2008, 2009, 2012; Pitari et al., 2014). Here we provide a preliminary assessment of ozone loss from geoengineering injection of alumina and diamond solid particles. To enable a relative comparison of the ozone impact of sulfate geoengineering, we use the same model to compute changes in ozone abundance arising from injections of both solid particles and of sulfate aerosols. We use the AER 2-D chemistry-transport-aerosol model which includes full ozone chemistry, with 50 transported species, an additional 51 radical species, 286 two- and three-body chemical reactions, 89 photolysis reactions, and 16 rainout/washout removal processes coupled to our aerosol model (Weisenstein et al., 1998, 2004; Rinsland et al., 2003). Reaction rates are from the Jet Propulsion Laboratory (JPL) compendium (Sander et al., 2011). The model parameterizes polar stratospheric clouds (PSCs) using thermodynamic equilibrium, employing the formulas of Hanson and Mauersberger (1988) and Marti and Mauersberger (1993) for equilibrium vapor pressures over solid $\mathrm{HNO}_{3}$ and ice, respectively, assuming no supersaturation and prescribing the particle radii. A comparison with observed ozone trends between 1979 and 2000 is presented in Anderson et al. (2006) for the AER model and several other models. Our simulations of ozone change due to $\mathrm{SO}_{2}$ injections are similar to those of Heckendorn et al. (2009) if we compare equivalent scenarios, but larger than those of Tilmes et al. (2012). This model does not include radiative or dynamical feedbacks; temperature and circulation are fixed with a climatology averaged over the years 1978 through 2004. Thus our evaluation of ozone changes due to geoengineering by the injection of solid particles includes only chemical perturbations due to heterogeneous reactions on particle surfaces and not due to changes in temperature or dynamics induced by the geoengineering.

The amount of ozone loss induced by stratospheric aerosols is strongly dependent on the concentrations of halogen species, primarily $\mathrm{Cl}$ and $\mathrm{Br}$. Future concentrations of halogens are expected to decline as a result of emissions controls, so the impact of stratospheric aerosols on ozone will - all else being equal - decline over time. To err on the side of caution by overstating the ozone impacts, we use present-day trace gas concentration throughout this study with 3.4 ppbv of total chlorine and 23 pptv of total bromine, including $6 \mathrm{pptv}$ of inorganic bromine derived from the very short-lived (VSL) organic compounds $\mathrm{CH}_{2} \mathrm{Br}_{2}$ and $\mathrm{CHBr}_{3}$. Tilmes et al. (2012) showed that inclusion of VSL bromine increases ozone depletion in geoengineering scenarios. A more detailed evaluation of ozone impacts of solid particle geoengineering will await further studies with coupled aerosol-chemistry-climate models.

Aerosol surface area density (SAD in units of $\mu \mathrm{m}^{2} \mathrm{~cm}^{-3}$ ) contributes to determining the rates of heterogeneous chemical reactions that occur on particle surfaces. Heterogeneous reactions may occur on bare alumina surfaces in the stratosphere, as well as on sulfate surfaces. The reaction $\mathrm{ClONO}_{2}+\mathrm{HCl} \rightarrow \mathrm{Cl}_{2}+\mathrm{HNO}_{3}$ has been measured on alumina surfaces (Molina et al., 1997; Sander et al., 2011) and would be expected to cause ozone depletion (Danilin et al., 2001; Jackman et al., 1998), though uncertainties in this reaction and the surface properties of alumina aerosol remain unexplored. Figure 8 shows bare alumina surface area density for the cases with $1 \mathrm{Tg} \mathrm{yr}^{-1}$ injection of $80 \mathrm{~nm}$ monomers (left panel) and $240 \mathrm{~nm}$ monomers (right panel). Alumina $\mathrm{SAD}$ is largest in the tropics where particles are injected, and is lower at higher latitudes where a larger fraction of the surfaces are coated with sulfate. Alumina SAD extends 
to higher altitudes, up to $40 \mathrm{~km}$ and above, with injection of $80 \mathrm{~nm}$ monomers, whereas the $240 \mathrm{~nm}$ monomers and their fractal derivatives sediment fast enough to preclude significant SAD above $30 \mathrm{~km}$. Note that sulfate aerosols generally evaporate above about $35 \mathrm{~km}$ altitude, and thus geoengineering with solid particles may introduce significant surface area density in regions that currently are not greatly impacted by heterogeneous chemistry.

Figure 9 shows sulfate SAD from the calculated background atmosphere without geoengineering (panel a) and the increase in sulfate SAD in an atmosphere with $1 \mathrm{Tg} \mathrm{yr}^{-1}$ of geoengineering injection of $80 \mathrm{~nm}$ alumina monomers (panel b) or $240 \mathrm{~nm}$ alumina monomers (panel c). While the addition of alumina particles has produced only a small change in the total stratospheric condensed sulfate (see Fig. 5b), it has produced significant increases in sulfate surface area density. This is a result of sulfate being distributed in thin layers on the surfaces of alumina particles. With injection of $80 \mathrm{~nm}$ monomers, the sulfate SAD has increased by factors of 2-4 in the lower stratosphere, with maximum SAD at high latitudes where significant concentration of complex alumina fractals exist to scavenge the smaller sulfate particles. With injection of $240 \mathrm{~nm}$ monomers, the maximum sulfate SAD occurs in the tropics as the faster sedimentation of alumina in this case results in a smaller concentration of mostly monomers at high latitudes. Figure 9 (panel d) shows the increase in sulfate SAD for a geoengineering scenario with $1 \mathrm{Tg} \mathrm{yr}^{-1}$ of $\mathrm{SO}_{2}$ injection as calculated by the AER 2-D model. The SAD increase is similar in magnitude to the case with injection of $80 \mathrm{~nm}$ alumina monomers, but has a distribution similar to the $240 \mathrm{~nm}$ alumina injection case. A similar injection of sulfur as $\mathrm{H}_{2} \mathrm{SO}_{4}$, as in Pierce et al. (2010), produces more than double this SAD increase. For reactions whose rate is dominated by liquid sulfate surface area density, we would expect similar chemical ozone loss from similar changes in sulfate $\mathrm{SAD}$ whether due to geoengineering by $\mathrm{SO}_{2}, \mathrm{H}_{2} \mathrm{SO}_{4}$, or alumina injection.

The SAD generated by alumina geoengineering is reduced when the monomer size of the injected particles increases. Optimizing the injected monomer size would be an important strategy to minimize stratospheric ozone depletion. Figure 10 illustrates this, showing annual averaged SAD between 15 and $25 \mathrm{~km}$ for bare alumina (panel a) and total sulfate (pure sulfate plus sulfate-coated alumina, panel b) as a function of injection rate with injections of $80,160,240$, and $320 \mathrm{~nm}$ monomers. The SAD for bare alumina drops by factors of 1.8 to 3.1, depending on injection rate, when the monomer size is increased from $80 \mathrm{~nm}$ to $160 \mathrm{~nm}$. The alumina SAD is roughly linear with injection rate, since the alumina surface area density does not decrease as particles coagulate when $D_{h}=2.0$. The total sulfate SAD (Fig. 10b) is even more dependent on monomer diameter than the uncoated alumina SAD is. Even though the burden of stratospheric sulfate on alumina varies slowly with injection rate, the sulfate SAD varies more rapidly with injection rate as the sulfate becomes spread more thinly over a greater numbers of alumina particles. The dashed lines in Fig. 10 represent cases where the coated particles take on a more compact fractal shape, and thus sediment faster, greatly decreasing sulfate SAD for the 80 and $160 \mathrm{~nm}$ injection cases. Our diamond simulation is similar to the alumina simulation with injection of $160 \mathrm{~nm}$ monomers.

Our model evaluation of ozone impacts from alumina geoengineering considers the following reaction on bare alumina surfaces:

$\mathrm{ClONO}_{2}+\mathrm{HCl} \rightarrow \mathrm{HNO}_{3}+\mathrm{Cl}_{2}$.

This reaction, with reaction probability $\gamma$ of 0.02 , has been studied in relation to ozone depletion resulting from space shuttle launches (Danilin et al., 2001; Jackman et al., 1998). We assume that this reaction occurs catalytically with no surface poisoning. Other potential reactions on alumina surfaces have been investigated in the laboratory (see Sander et al., 2011), and further investigation is needed to determine how additional heterogeneous and photocatalytic reactions could modify stratospheric chemistry or change the surface properties of alumina in the stratosphere. Measurements of potential heterogeneous reactions on diamond surfaces are not available. Thus we perform diamond injection calculations assuming Reaction (R1) on diamond at the same rate as for alumina, and assuming no reactions on bare diamond surfaces.

We also consider heterogeneous reactions on the sulfatecoated surfaces of solid particles. These reactions include

$$
\begin{aligned}
& \mathrm{N}_{2} \mathrm{O}_{5}+\mathrm{H}_{2} \mathrm{O} \rightarrow 2 \mathrm{HNO}_{3} \\
& \mathrm{ClONO}_{2}+\mathrm{HCl} \rightarrow \mathrm{HNO}_{3}+\mathrm{Cl}_{2} \\
& \mathrm{ClONO}_{2}+\mathrm{H}_{2} \mathrm{O} \rightarrow \mathrm{HNO}_{3}+\mathrm{HOCl} \\
& \mathrm{HOCl}+\mathrm{HCl} \rightarrow \mathrm{H}_{2} \mathrm{O}+\mathrm{Cl}_{2} \\
& \mathrm{BrONO}_{2}+\mathrm{H}_{2} \mathrm{O} \rightarrow \mathrm{HNO}_{3}+\mathrm{HOBr} \\
& \mathrm{BrONO}_{2}+\mathrm{HCl} \rightarrow \mathrm{HNO}_{3}+\mathrm{BrCl} \\
& \mathrm{HOBr}+\mathrm{HCl} \rightarrow \mathrm{H}_{2} \mathrm{O}+\mathrm{BrCl} \\
& \mathrm{HOBr}+\mathrm{HBr} \rightarrow \mathrm{H}_{2} \mathrm{O}+\mathrm{Br}_{2} .
\end{aligned}
$$

Due to the solubility of $\mathrm{HCl}, \mathrm{ClONO}_{2}, \mathrm{HOCl}$, and $\mathrm{HOBr}$ in sulfuric acid solutions, Reactions (R3), (R4), (R5), and (R8) can be considered bulk processes or hybrid bulk-surface processes governed by a reaction-diffusion process. For liquid spherical particles we use standard methods to calculating the reaction probability as a function of radius (Shi et al., 2001). For reactions on coated solid particles, we use the same functions, substituting the thickness of the sulfate layer in place of the radius of a spherical particle.

Calculated changes in ozone due to heterogeneous reactions on alumina surfaces (bare alumina and sulfate-coated alumina) are shown in Fig. 11 for cases with injection of 80 and $240 \mathrm{~nm}$ monomers at an injection rate of $1 \mathrm{Tg} \mathrm{yr}^{-1}$. Column ozone depletion ranges from $2 \%$ in the tropics to $6-$ 

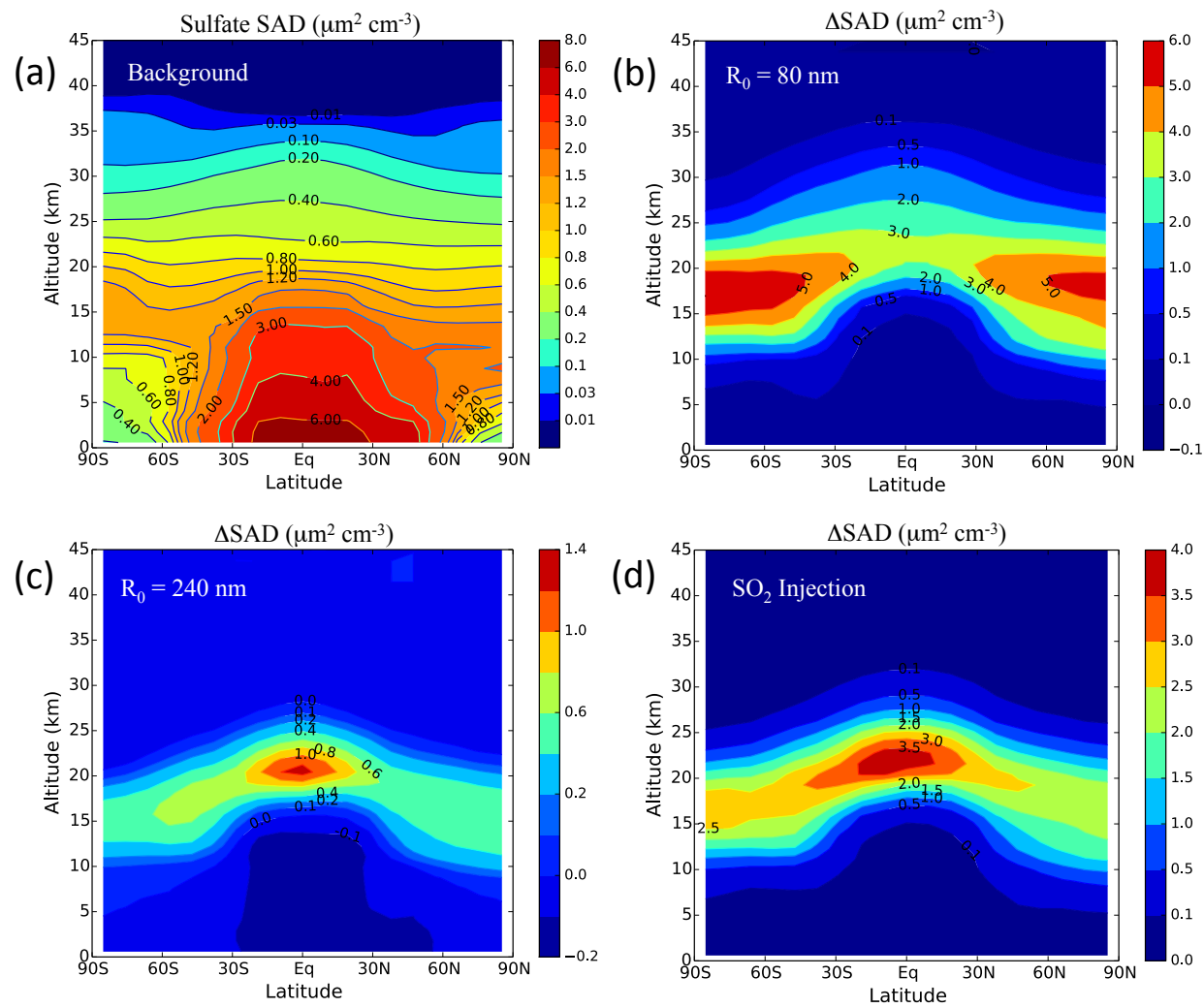

Figure 9. Calculated annual average sulfate surface area density $\left(\mu \mathrm{m}^{2} \mathrm{~cm}^{-3}\right)$ of (a) sulfate particles without geoengineering, and surface area density increase $\left(\mu \mathrm{m}^{2} \mathrm{~cm}^{-3}\right)$ with geoengineering injections of (b) $1 \mathrm{Tg} \mathrm{yr}^{-1}$ of $80 \mathrm{~nm}$ alumina monomers and (c) $1 \mathrm{Tg} \mathrm{yr}{ }^{-1}$ of $240 \mathrm{~nm}$ alumina monomers. Panel (d) shows sulfate aerosol surface area density increase $\left(\mu \mathrm{m}^{2} \mathrm{~cm}^{-3}\right)$ with $1 \mathrm{Tg} \mathrm{yr}^{-1}$ of SO$_{2}$ injection.
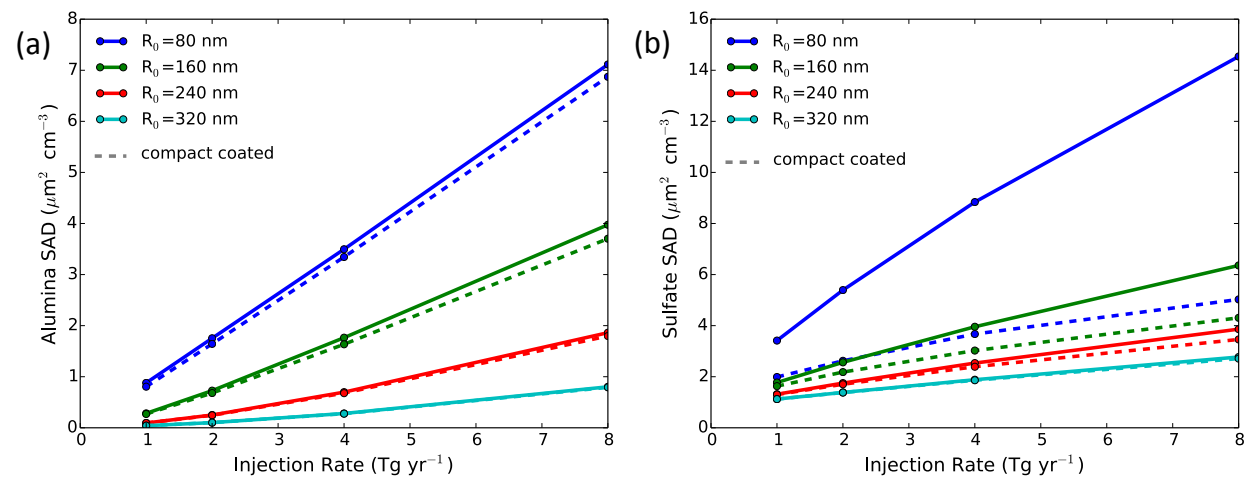

Figure 10. Global annual average stratospheric surface area density between 15 and $25 \mathrm{~km}$ altitude for (a) uncoated alumina, and (b) total sulfate. The dashed lines represent simulations in which the coated alumina particles are assumed to become more compact in shape.

$10 \%$ at mid-latitudes and up to $14 \%$ at the poles in springtime with the injection of $80 \mathrm{~nm}$ monomers. With the injection of $240 \mathrm{~nm}$ monomers, ozone depletion is much smaller, ranging from 0.3 to $2.5 \%$. The annual average ozone change as a function of latitude and altitude (Fig. 11, right hand panels) shows features linked to local balances in ozone's formation rate, chemical destruction rate, and local transport rates. In the tropics, ozone concentrations are determined by the chemical production via UV radiation that is balanced by transport out of the tropics to higher latitudes. Thus ozone changes due to increased loss mechanisms are minimal in the tropics in the stratosphere, though increased penetration of UV to lower altitudes in the tropics can produce ozone increases. In the middle stratosphere at $25-35 \mathrm{~km}$ altitude, the $\mathrm{NO}_{x}$ cycle dominates ozone loss. Increases in aerosol surface area density in this region reduce $\mathrm{NO}$ and $\mathrm{NO}_{2}$ while increasing $\mathrm{HNO}_{3}$ via the $\mathrm{N}_{2} \mathrm{O}_{5}+\mathrm{H}_{2} \mathrm{O}$ reaction. Thus the $\mathrm{NO}_{x}$ loss cycle is diminished and ozone increases. The sedimen- 

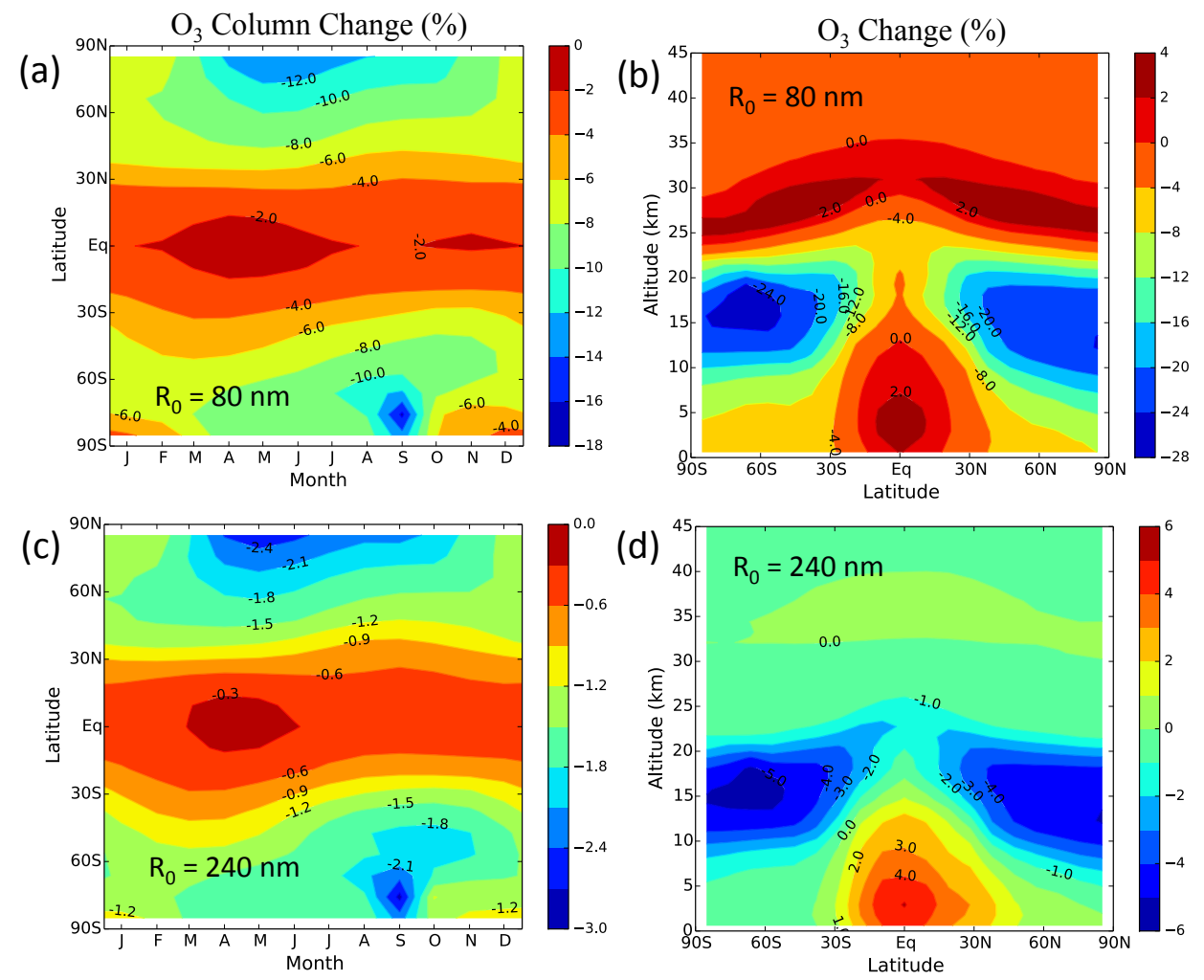

Figure 11. Ozone changes due to the injection of alumina aerosol. Column ozone changes (\%) are shown as a function of latitude and month (left panels) and annual average local ozone changes $(\%)$ as a function of latitude and altitude (right panels). Results are shown for an injection rate of $1 \mathrm{Tg} \mathrm{yr}^{-1}$ of $80 \mathrm{~nm}$ (top panels) and $240 \mathrm{~nm}$ (bottom panels) alumina monomers. Note ozone increases in the upper stratosphere where the $\mathrm{NO}_{x}$ cycle dominates, and decreases in the lower stratosphere where the $\mathrm{ClO}_{x}$ and $\mathrm{BrO}_{x}$ cycles dominate.

tation rate of alumina particles is significant, as the scenario with the injection of $80 \mathrm{~nm}$ monomers yields significant increases in aerosol surface area density and ozone changes above $25 \mathrm{~km}$, whereas the scenario with $240 \mathrm{~nm}$ monomers injected does not. In the lower stratosphere at mid-latitudes and high latitudes, the heterogeneous reactions on particle surfaces increase the ratio of chlorine and bromine in their radical forms that destroy ozone $(\mathrm{Cl}, \mathrm{ClO}, \mathrm{Br}$, and $\mathrm{BrO})$. In addition, the $\mathrm{N}_{2} \mathrm{O}_{5}+\mathrm{H}_{2} \mathrm{O}$ reaction leads to more $\mathrm{HNO}_{3}$ and less $\mathrm{ClONO}_{2}$ and $\mathrm{BrONO}_{2}$, thus indirectly increasing halogen radicals as well. Local ozone depletions in the lower stratosphere are as large as $24 \%$ with $80 \mathrm{~nm}$ monomer injections and $5 \%$ with $240 \mathrm{~nm}$ monomer injections, on an annual average basis.

Figure 12a shows annual average changes in ozone column as a function of latitude with $1 \mathrm{Tg} \mathrm{yr}^{-1}$ of geoengineering injections. Results with the injection of 80,160 , and $240 \mathrm{~nm}$ alumina monomers are shown, along with the injection of $160 \mathrm{~nm}$ diamond monomers. We do not calculate ozone changes due to the injection of $320 \mathrm{~nm}$ alumina monomers because these scenarios produce less radiative forcing than the injection of $240 \mathrm{~nm}$ monomers for similar injection rates. Ozone changes, similar to SAD increases, are found to be very sensitive to injected monomer size. However, assuming that coated alumina particles assume a more compact shape (shown by dashed lines in the figure) significantly reduces calculated ozone depletion for the $R_{0}=80 \mathrm{~nm}$ case, and modestly reduces ozone depletion for the $R_{0}=160 \mathrm{~nm}$ case. Also shown in Fig. 12a are changes in ozone column due to the injection of $1 \mathrm{Tg} \mathrm{yr}^{-1}$ of $\mathrm{SO}_{2}$ and $\mathrm{H}_{2} \mathrm{SO}_{4}$, which are roughly similar to those calculated with $1 \mathrm{Tg} \mathrm{yr}^{-1}$ of $80 \mathrm{~nm}$ alumina monomers.

Figure $12 \mathrm{~b}$ shows calculated ozone changes for injection rates of $1,2,4$, and $8 \mathrm{Tg} \mathrm{yr}^{-1}$ with the injection of $240 \mathrm{~nm}$ alumina monomers. Note than ozone changes increase at a less than linear rate with increasing injection rates, and that the effect of compaction of coated alumina particles becomes more significant at higher injection rates due to the formation of higher-order fractals. Figure 12c shows calculated ozone changes due to geoengineering injection of diamond monomers of $160 \mathrm{~nm}$ radius. Solid lines are for results including the Reaction (R1) on uncoated particles, and dotted lines omit this reaction. Reaction (R1) has a greater effect in the tropics than at mid-latitudes due to higher concentrations of uncoated particles there. The northern high latitudes show greater sensitivity to geoengineering injections than the southern high latitudes at the higher emission levels, likely due to the dominant role of PSCs over the Antarctic. 

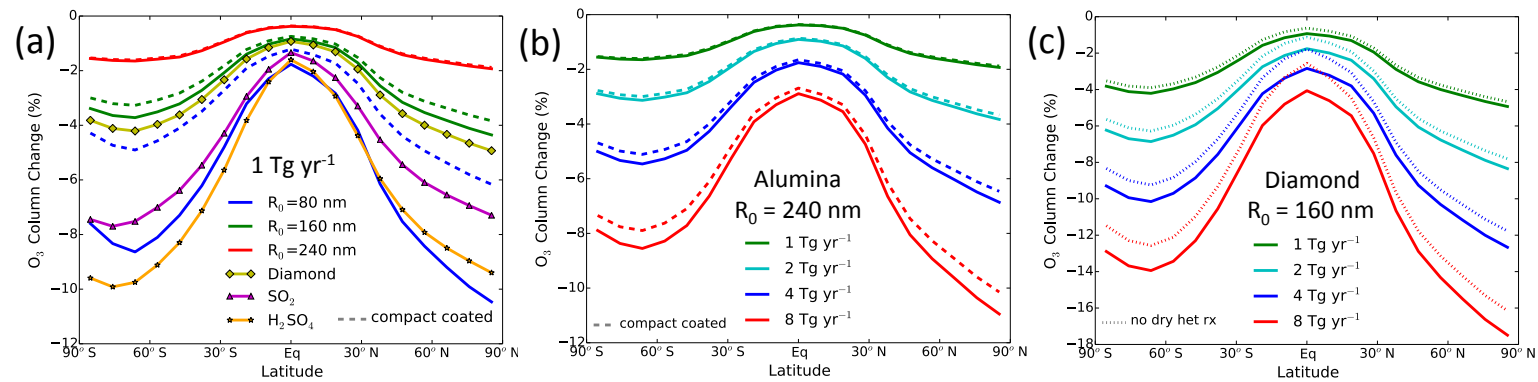

Figure 12. Annual average column ozone change in percent as a function of latitude for (a) cases with $1 \mathrm{Tg} \mathrm{yr}^{-1}$ injections of alumina monomers of $80 \mathrm{~nm}, 160 \mathrm{~nm}$, and $240 \mathrm{~nm}$, and diamond monomers of $160 \mathrm{~nm}$ and $\mathrm{SO}_{2}$ and $\mathrm{H}_{2} \mathrm{SO}_{4}$, (b) cases with injection of $240 \mathrm{~nm}$ alumina monomers at rates of $1,2,4$, and $8 \mathrm{Tg} \mathrm{yr}^{-1}$, and (c) cases with injection of $160 \mathrm{~nm}$ diamond monomers at rates of $1,2,4$, and $8 \mathrm{Tg} \mathrm{yr}^{-1}$. Cases in which coated particles are assumed to become more compact in shape are shown with dashed lines in panels (a) and (b). For diamond, cases without Reaction (R1) occurring on dry diamond particle surfaces are shown with dotted lines in panel (c).
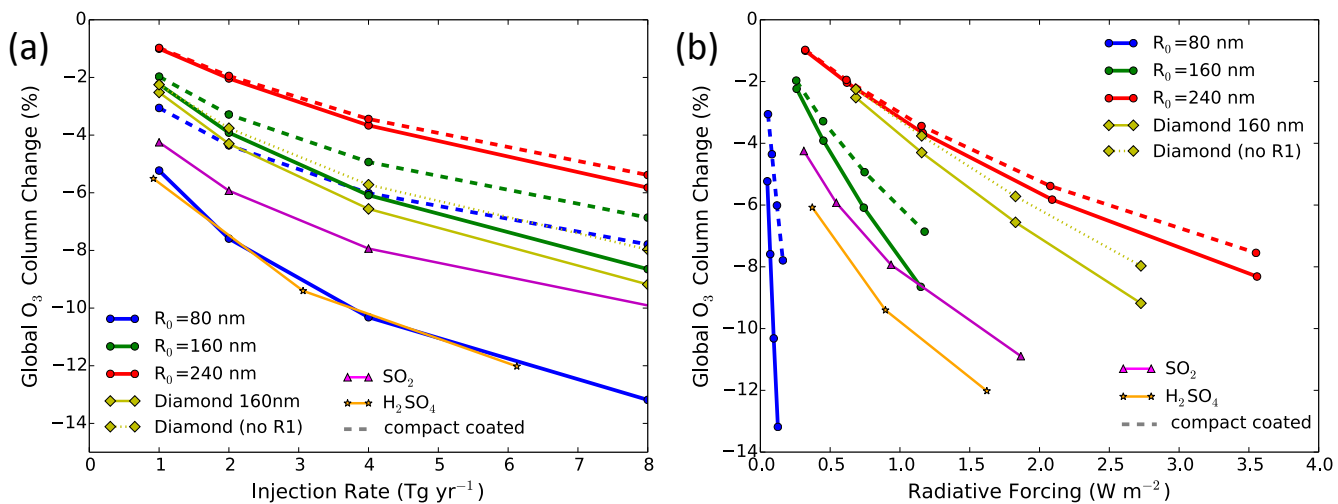

Figure 13. Global annual average column ozone change (in percent) (a) as a function of injection rate and (b) as a function of associated shortwave radiative forcing. Ozone change for diamond is shown with and without Reaction (R1) on uncoated diamond particles. Calculations with $\mathrm{SO}_{2}$ and $\mathrm{H}_{2} \mathrm{SO}_{4}$ injections employ the same model to calculate radiative forcing and ozone depletion as for alumina and diamond.

Global average column ozone changes are shown in Fig. 13a as functions of injected monomer size and injection rate. Figure 13b shows changes in global average ozone as a function of the associated shortwave radiative forcing for each scenario. This makes it clear that geoengineering injection of $80 \mathrm{~nm}$ alumina monomers is completely unworkable, producing excessive ozone depletion $\left(5 \%\right.$ with $1 \mathrm{Tg} \mathrm{yr}^{-1}$ injection and $14 \%$ with $8 \mathrm{Tg} \mathrm{yr}^{-1}$ injection) and minimal radiative forcing. Geoengineering by injection of $240 \mathrm{~nm}$ alumina monomers, however, could potentially be an effective climate control strategy, similar to geoengineering by injection of sulfur in its radiative forcing effectiveness but with less ozone depletion potential. Note that radiative forcing and associated ozone depletion with $16 \mathrm{Tg} \mathrm{yr}^{-1}$ injection of $240 \mathrm{~nm}$ alumina monomers is included in Fig. 13b, yielding $-3.6 \mathrm{~W} \mathrm{~m}^{-2}$ of RF with about $8 \%$ ozone depletion. Injection of $160 \mathrm{~nm}$ diamond monomers produces ozone loss per teragram of injection similar to $160 \mathrm{~nm}$ alumina monomers, but with radiative forcing per teragram of injection greater than for similar injections of $240 \mathrm{~nm}$ alumina monomers. We show diamond results both including and excluding Reac- tion (R1) on bare diamond surfaces. This reaction makes about a $10-15 \%$ difference in ozone depletion due to diamond injection. Note that the $\mathrm{SO}_{2}$ results plotted in Fig. 13 show more ozone depletion than in Heckendorn et al. (2009) because that study did not include the short-lived bromine source gases and used a narrower injection region. More studies will be needed to evaluate potential impacts on stratospheric chemistry such as tropopause heating and changes in the Brewer-Dobson circulation that are not evaluated here.

\section{Discussion}

We have developed a new aerosol model and used it to quantitatively explore the interactions of solid particles with sulfate aerosol in the stratosphere. This analysis allows a preliminary assessment of some of the trade-offs that might arise in using solid aerosols such as alumina or diamond rather than sulfates for solar geoengineering. We first discuss salient limitations of our model before turning to analysis of trade-offs. 


\subsection{Limitations}

\subsubsection{Injection mechanism}

We do not model the mechanism for injection and dispersion of aerosols. If aerosols were injected from aircraft, there would be small-scale dynamical effects in the injection nozzle and in the aircraft plume in which particle concentrations would be much larger than found after dilution to the scale of a model grid box, possibly leading to rapid coagulation. Effects during particle generation or injection from a nozzle would occur on very short scales of time and space and cannot be estimated here. We can, however, estimate the impact of coagulation in an expanding plume using the method of Pierce et al. (2010). We allow the plume cross section to dilute from $6 \mathrm{~m}^{2}$ to $17 \times 10^{6} \mathrm{~m}^{2}$ over a $48 \mathrm{~h}$ period, assuming that alumina particles are released at a rate of $30 \mathrm{~kg} \mathrm{~km}^{-1}$ of flight path. We find the fraction of alumina mass remaining as monomers after $48 \mathrm{~h}$ of plume dilution to be 37,86 , 96 , and $98 \%$ for injected monomers of $80,160,240$, and $320 \mathrm{~nm}$, respectively. For monomer injections of 240 and $320 \mathrm{~nm}$, only two-monomer fractals are created within $48 \mathrm{~h}$. We conclude that plume dynamics and processing are unlikely to have a substantial effect on alumina geoengineering if injected monomer size is greater than $160 \mathrm{~nm}$. For $240 \mathrm{~nm}$ monomer, the most relevant case, our 2-D model calculation would be expected to have $4 \%$ less mass in monomers if plume dynamics were considered.

\subsubsection{Two-dimensional model}

A second limitation is the use of a 2-D model. Since the geoengineering scenarios discussed in this work deal with particle injection in the $20-25 \mathrm{~km}$ altitude region and spread between $30^{\circ} \mathrm{S}$ and $30^{\circ} \mathrm{N}$, assuming zonal symmetry, as a 2$\mathrm{D}$ model implicitly does, does not detract greatly from the validity of our results. In particular, if the method of injecting alumina particles attempts to distribute them uniformly in space and time and avoid overlapping emissions as much as possible, then a zonally symmetric spread may be a fairly good approximation. However, details of transport near and below the tropopause are not well-represented in 2-D models. Thus a 3-D model would be needed to accurately represent this region. And if a specific geoengineering injection methodology were to be investigated, a 3-D model with fine resolution would be needed to examine heterogeneities in the resulting aerosol distribution.

\subsubsection{Geometry of aggregates, effects of size binning}

The fractal geometry of aggregates likely depends on the formation mechanism, and it is plausible that the actual fractal dimensions might differ significantly from the $D_{\mathrm{f}}$ value of 1.6 we use here for alumina and diamond. While the fractal dimension of alumina has been measured for monomer cores much smaller than considered here, that of diamond has not. It is also plausible that variables $k_{\mathrm{f}}$ and $k_{h}$ should have values other than 1.0, at least for cases that calculate many high-order fractals. The behavior of aggregates under stratospheric conditions has not been studied extensively. The formulations we have adopted for coagulation, condensation, and sedimentation are based on theoretical studies or on tropospheric or liquid-medium experiments, and thus should be considered uncertain. Our formulation also assumes that all injected monomers are of a uniform radius. While it appears reasonable to assume that industrial production of alumina or diamond nanoparticles could produce particles within a narrow size range, our assumption is a simplification. Likewise, our assumption of maximal compaction instantaneously on wetting is likely not realistic but meant to show the greatest possible effect of potential particle compaction on aging. Observational studies in the laboratory and in the stratosphere would be needed to determine whether compaction of alumina particles occurs and to what extent. However, compaction has a minor effect on the radiative properties and ozone depletion potential of particles with monomer sizes of $\sim 200 \mathrm{~nm}$ or greater.

Numerical errors result from the discrete aerosol size binning we employ. The discretization leads to a broadening of the size distribution during the coagulation process. Appendix A details the coagulation methodology, in which coagulation of two solid particles often leads to a new particle with size intermediate between two bins. In this case, particle mass is apportioned between two bins, leading to mass transfer into a bin larger than that of the combined new particle. This broadening of the distribution will lead to somewhat excessive sedimentation, whose error depends on the coarseness of the bin spacing. Coagulation between liquid and solid particles does not produce numerical broadening of the size distribution as the binning for mixed solid-liquid particles depends only on the size of the solid particle.

\subsubsection{Ozone chemistry}

The surface chemistry of alumina and other solid particles potentially useful for geoengineering has not been studied as extensively as that of sulfate particles. We include only one reaction, $\mathrm{ClONO}_{2}+\mathrm{HCl}$, on alumina and diamond particles in this modeling study. Laboratory studies have investigated some additional reactions on alumina surfaces, and there may be others not yet explored. Reported reactions on $\mathrm{Al}_{2} \mathrm{O}_{3}$ surfaces include the uptake of $\mathrm{NO}_{2}$ and $\mathrm{HNO}_{3}$ and reactions of several volatile organic compounds, including formaldehyde, methanol, and acetic acid (Sander et al., 2011). In addition, photocatalysis reactions of several species on $\mathrm{Al}_{2} \mathrm{O}_{3}$ surfaces have been reported (De Richter and Caillol, 2011), and may depend on the exact composition or impurities of the particle surface. Photocatalysis of chlorofluorocarbons (CFC) compounds has been considered as a method to mitigate the atmospheric burden of greenhouse gases if augmented by artificial UV radiation in the troposphere. However, if these 
reactions were effective in the stratosphere, they would contribute to the formation of free radical chlorine and bromine, possibly increasing ozone depletion, while reducing the lifetime the CFCs. Studies of these and other reactions under stratospheric photochemical conditions would need to be performed on any solid particle under consideration for geoengineering application.

\subsubsection{Missing feedbacks}

The modeling we present utilizes temperature and transport fields uncoupled from the model's chemistry and aerosols and is therefore missing a number of feedback processes that may be important in the atmosphere and may significantly change the radiative forcing or ozone depletion estimates given here. These include changes in stratospheric temperature due to aerosol heating, which would modify rates of reactions important to ozone formation and loss. Aerosol heating and enhanced equator-pole temperature gradients would also modify the strength of the Brewer-Dobson circulation and the polar vortex, with impacts on aerosol concentration, PSC formation, and ozone concentration. Increases in the temperature of the tropical tropopause layer would increase the transport of water vapor across the tropopause, increasing stratospheric $\mathrm{H}_{2} \mathrm{O}$ and $\mathrm{OH}$ concentrations, and reducing ozone (Heckendorn et al., 2009). These additional ozone changes would further modify stratospheric temperature and circulation. However, Heckendorn et al. (2009) found that ozone loss due to heterogeneous chemistry, without the dynamical effects of changes in temperature, water vapor, and the Brewer-Dobson strength, accounted for $75 \%$ of the ozone change.

A more uncertain feedback process is the effect of enhanced aerosol concentrations on upper tropospheric cloudiness and cloud radiative properties (Kuebbeler et al., 2012; Cirisan et al., 2013). A general circulation model with stratospheric chemistry and aerosol and cloud microphysics would be needed to evaluate these feedback effects.

\subsection{Principal findings}

Use of alumina particles for SRM is potentially useful only if the size of the injected monomers is larger than about $150 \mathrm{~nm}$; the best results are only seen if the monomer radius exceeds about $200 \mathrm{~nm}$. The strong dependence on monomer size can be understood if one assumes that the injection rate will be adjusted so as to produce a given radiative forcing, for example $-2 \mathrm{~W} \mathrm{~m}^{-2}$. For alumina, the peak mass-specific upscattering efficiency occurs at a radius of $\sim 200 \mathrm{~nm}$ (see Fig. 6b). As the monomer size gets smaller a higher monomer density and mass injection rate is required to maintain the specified radiative forcing. The coagulation rate increases as the square of monomer density, so the fraction of monomers in aggregates increase rapidly with monomer density. Finally, the mass-specific radiative forcing for aggregates de- creases quickly with the number of monomers in an aggregate (see Fig. 7a), so the injection rate must be increased further to maintain a fixed radiative forcing. The net effect is that the radiative efficacy, the global radiative forcing per unit mass injection rate, declines very rapidly for particle radii below $150 \mathrm{~nm}$. We find that alumina monomers with radii of roughly $240 \mathrm{~nm}$ provide the most radiative forcing for a given injection rate. For particle sizes beyond $240 \mathrm{~nm}$, the scattering efficiency remains roughly constant while the sedimentation rate increases, contributing to a decrease in radiative forcing efficiency per unit injection rate.

As a specific example, consider the injection of $240 \mathrm{~nm}$ alumina monomers at a rate of $4 \mathrm{Tg} \mathrm{yr}^{-1}$ evenly distributed between $30^{\circ} \mathrm{S}$ to $30^{\circ} \mathrm{N}$ and from 20 to $25 \mathrm{~km}$ in altitude. This produces a stratospheric burden of $4.6 \mathrm{Tg}$ (see Fig. 5a) and global radiative forcing of $-1.2 \mathrm{~W} \mathrm{~m}^{-2}$ (see Fig. 7b). Under these conditions, coagulation of alumina particles is minimal: $81 \%$ of the alumina is in monomers and only $4 \%$ is in aggregates of more than two monomers (see Fig. 4c). Particle densities are a maximum in the lower tropical stratosphere with peak concentrations of about $4 \mathrm{~cm}^{-3}$. The net effect of interaction with the background stratospheric sulfate is that about $50 \%$ of the stratospheric sulfate is found as a coating (Fig. 5b, right axis) with a typical depth of order $10 \mathrm{~nm}$ on the alumina particles. The total sulfate burden is reduced from 0.11 to $0.08 \mathrm{Tg}$ (Fig. 5b, left axis) because the relatively fast fall speeds of the alumina aerosol provide a sedimentation sink for sulfates, yet the sulfate surface area density is increased by an average of $2 \mu \mathrm{m}^{2} \mathrm{~cm}^{-3}$ in the lower stratosphere (Fig. 10b). The annual global average ozone column is reduced by $3.7 \%$ (Fig. 13a) with maximum ozone loss of 4 to $7 \%$ over polar regions for this scenario and the given modeling assumptions.

As with sulfate aerosols, ozone concentrations increase at altitudes around $30 \mathrm{~km}$ in the mid-stratosphere where the $\mathrm{NO}_{x}$ cycle dominates but this is more than compensated by the halogen-catalyzed ozone loss in the lower stratosphere. And with the injection of $240 \mathrm{~nm}$ monomers, sedimentation is rapid enough to preclude significant aerosol concentrations above $25-30 \mathrm{~km}$. Most of the ozone impact of alumina aerosols is found to be due the increase in sulfate surface area and heterogeneous reactions on the liquid sulfuric acid. This is because most of the alumina particles are coated with sulfate at mid-latitudes and high latitudes where ozone loss reactions largely determine the ozone concentration. If the rate of Reaction (R1) is set to zero in our simulations, the column ozone depletion changes by less than $15 \%$ in the extratropics, but up to $35 \%$ in the tropics with injection $4 \mathrm{Tg} \mathrm{yr}^{-1}$ of $240 \mathrm{~nm}$ alumina monomers. Thus uncertainty in the rate of Reaction (R1) or the nature of the uncoated alumina surface does not have a strong influence on our calculated ozone impacts. If we assume that the alumina particle surfaces remain uncoated and that Reaction (R1) occurs on all alumina particles, we find that the ozone depletion is much less than that obtained when the surfaces do become coated, implying that 
Reaction (R1) on alumina surfaces has less effect on ozone than sulfate heterogeneous reactions on the same surface area do, mostly due to the effectiveness of heterogeneous bromine reactions.

We can achieve a similar radiative forcing of $-1.2 \mathrm{~W} \mathrm{~m}^{-2}$ with the injection of $160 \mathrm{~nm}$ radius diamond monomers at $2 \mathrm{Tg} \mathrm{yr}^{-1}$. This injection rate produces a stratospheric burden of $3.3 \mathrm{Tg}$ of diamond. The corresponding ozone depletion due to diamond injection ranges between $3.8 \%$ globally, due to increased sulfate surface area alone, and $4.3 \%$ when we assume that Reaction (R1) occurs on the bare surface of diamond particles with the same reaction rate employed for alumina. However, levels of ozone depletion are highly uncertain, as this reaction, and other potential heterogeneous reactions on diamond surfaces, have not been measured.

\subsection{Comparison with sulfate aerosols}

Whatever method is used to create an artificial radiative forcing, solar geoengineering is - at best - an imperfect method for reducing climate impacts. Any technology for producing radiative forcing will have a set of technology-specific impacts, such as ozone loss arising from the introduction of aerosol particles into the stratosphere. However the radiative forcing is produced, the efficacy of SRM is inherently limited by the fact that a change in solar radiative forcing cannot perfectly compensate for the radiative forcing caused by increasing greenhouse gases (Kravitz et al., 2014; Curry et al., 2014). A central motivation for considering solid aerosols rather than sulfates is that they might have less severe technology-specific risks. As discussed in the introduction, the principle technology-specific risks or side effects of sulfate aerosols are ozone loss, increased diffuse light, and stratospheric heating.

Loss of stratospheric ozone and an increase in diffuse light have direct impacts on ecosystems and human health. The consequences of stratospheric heating are indirect and more speculative. Heating of the tropical tropoause layer (TTL) might be expected to increase the amount of water vapor entering the stratosphere. An increase in TTL temperature of $1 \mathrm{~K}$ increases the concentration of water vapor entering the stratosphere by about 0.8 ppmv (Kirk-Davidoff, 1999). Geoengineering with sulfate aerosols might heat the TTL region by several degrees, increasing stratospheric water vapor concentrations by more than 2 ppmv (Heckendorn et al., 2009). This would in turn exacerbate ozone loss and create a positive radiative forcing that would offset some of the reduction in forcing from SRM. While there is uncertainty about the exact consequences of heating the lower stratosphere, it is reasonably certain that all else being equal, a geoengineering method that does not heat the low stratosphere is preferable to one that does.
We estimate stratospheric heating for alumina, diamond, and sulfate geoengineering scenarios with the RRTM model, as described in Sect. 3.4. Our results for alumina are broadly consistent with the results of Ferraro et al. (2011) for titania. Note, however, that Ross and Sheaffer (2014) conclude that the positive infrared radiative forcing from alumina can be larger than the negative radiative forcing from solar scattering by the same particles. We suspect that part of this discrepancy comes from the fact that Ferraro et al. (2011) and this paper assume a narrow size distribution close to the optimal for solar scattering, whereas Ross and Sheaffer (2014) use a broad alumina size distribution. However, we have not resolved this discrepancy, so our estimate of heating for alumina should be taken as uncertain.

As shown in Table 2, our results suggest that alumina may have less severe technology-specific risks than sulfates. While the injected mass necessary to achieve a $-2 \mathrm{Wm}^{-2}$ radiative forcing is roughly equivalent whether employing alumina or sulfate aerosol, the ozone depletion is more severe with sulfate geoengineering. In addition, the increase in diffuse solar radiation would be half as much with alumina as with sulfate, and the stratospheric heating is expected to be considerably less, smaller by a factor of $4-5$ in our estimation. Diamond appears to offer excellent shortwave scattering with only a small increase in diffuse light. We estimate ozone depletion due to diamond to be less than that due to sulfate, but uncertainty is large. Lower stratospheric heating from diamond is quite small.

We conclude that SRM by the injection of solid particles may have some advantages relative to sulfates and merits further study to reduce the sizable uncertainties that currently exist. It is important to note that the injection of substances like alumina or diamond nanoparticles have much greater "unknown unknowns" than sulfates, as they would be novel substances in the stratosphere. Laboratory studies of reaction kinetics for these particles under stratospheric conditions, as well as studies of their microphysical and radiative properties, are required to reduce uncertainties. 
Appendix A: Microphysical schemes for coagulation and condensation

\section{A1 Coagulation}

\section{A1.1 Coagulation between particles of similar composition}

In our sectional aerosol representation, collisions between particles of similar composition in bins $i$ and $j$, where bin $j$ is smaller than bin $\mathrm{i}$, produce particles of size intermediate between bins $i$ and $i+1$. Since the volume ratio between size bins, $V_{\text {rat }}$, is 2.0 in our case, coagulation between two particles in bin $i$ yields one particle in bin $i+1$. The rate of coagulation between particles in bin $i$ and particles in bin $j, \beta_{i j}$, is a function of the coagulation kernel, $K_{i j}$, and the number densities of the particles in each bin, $N_{i}$ and $N_{j}$.

$\beta_{i j}=S N_{j} N_{i} K_{i j}$,

where $S=0.5$ if $i=j$, otherwise $S=1.0$. A coagulation event between a particle in bin $i$ and a particle in bin $j(j \leq i)$ changes particle number densities in three bins as follows:

$$
\begin{aligned}
& \frac{\mathrm{d} N_{j}}{\mathrm{~d} t}=-\beta_{i j} \\
& \frac{\mathrm{d} N_{i}}{\mathrm{~d} t}=-\beta_{i j} \frac{F}{\left(V_{\text {rat }}-1\right)} \\
& \frac{\mathrm{d} N_{i+1}}{\mathrm{~d} t}=+\beta_{i j} \frac{F}{\left(V_{\text {rat }}-1\right)},
\end{aligned}
$$

where $F=\frac{V_{j}}{V_{i}}$.

Coagulation of sulfate particles with other sulfate particles and of alumina particles with other alumina particles is generated by a double sum of the above equations over all bins $i$ and $j$, where $j \leq i$. Our explicit formulation generates $\frac{\mathrm{d} N}{\mathrm{~d} t}$ for all size bins before updating any values of $N$.

\section{A1.2 Coagulation between sulfate particles and solid particles}

Coagulation between pure sulfate particles and pure alumina particles transfers particles from the category of pure alumina to the category of coated alumina, and shifts sulfate mass from pure sulfate particles to coated alumina sulfate mass. Since coated alumina particles are binned by their alumina mass alone, the alumina size index is unchanged in this coagulation process. For coagulations between an alumina particle of bin $i$ and a sulfate particle of bin $j$, the rate of change of concentrations is

$$
\begin{aligned}
& \frac{\mathrm{d} N_{j}(\mathrm{~S})}{\mathrm{d} t}=-\beta_{i j} \\
& \frac{\mathrm{d} N_{i}(\mathrm{Al})}{\mathrm{d} t}=-\beta_{i j} \\
& \frac{\mathrm{d} N_{i}(c-\mathrm{Al})}{\mathrm{d} t}=+\beta_{i j}
\end{aligned}
$$

$\frac{\mathrm{d} M_{i}(\mathrm{~S}-\mathrm{Al})}{\mathrm{d} t}=+\beta_{i j} \mathrm{DS}_{j}$,

where $N(\mathrm{~S}), N(\mathrm{Al}), N(c-\mathrm{Al})$ represent number concentrations of pure sulfate, pure alumina, and coated alumina particles, respectively, $M(\mathrm{~S}-\mathrm{Al})$ represents the mass of sulfate on a coated alumina particle, and DS ${ }_{j}$ represents the mass of sulfate in a single pure sulfate particle of bin $j$. Coagulation between a pure sulfate particle of bin $j$ and a coated alumina particle of bin $i$ removes a sulfate particle and transfers its sulfate mass onto the coated alumina particle:

$$
\begin{aligned}
& \frac{\mathrm{d} N_{j}(\mathrm{~S})}{\mathrm{d} t}=-\beta_{i j} \\
& \frac{\mathrm{d} M_{i}(\mathrm{~S}-\mathrm{Al})}{\mathrm{d} t}=+\beta_{i j} \mathrm{DS}_{j} .
\end{aligned}
$$

\section{A1.3 Coagulation between different types of solid particles}

For coagulation between an uncoated and a coated alumina particle,

$$
\begin{aligned}
& \frac{\mathrm{d} N_{j}(\mathrm{Al})}{\mathrm{d} t}=-\beta_{i j} \\
& \frac{\mathrm{d} N_{i}(c-\mathrm{Al})}{\mathrm{d} t}=-\beta_{i j} \frac{F}{\left(V_{\mathrm{rat}}-1\right)} \\
& \frac{\mathrm{d} N_{i+1}(c-\mathrm{Al})}{\mathrm{d} t}=+\beta_{i j} \frac{F}{\left(V_{\mathrm{rat}}-1\right)} \\
& \frac{\mathrm{d} M_{i}(\mathrm{~S}-\mathrm{Al})}{\mathrm{d} t}=-\beta_{i j} \frac{F}{\left(V_{\mathrm{rat}}-1\right)} \mathrm{DSAl}_{i} \\
& \frac{\mathrm{d} M_{i+1}(\mathrm{~S}-\mathrm{Al})}{\mathrm{d} t}=+\beta_{i j} \frac{F}{\left(V_{\mathrm{rat}}-1\right)} \mathrm{DSAl}_{i},
\end{aligned}
$$

where $\mathrm{DSAl}_{i}$ represents the mass of sulfate on a single coated alumina particle of bin $i$, obtained as the ratio of total sulfate mass on solid particles of bin $i$ for a given grid box to the number of coated alumina particles in that grid box.

For coagulation between two coated alumina particles,

$$
\begin{aligned}
& \frac{\mathrm{d} N_{j}(c-\mathrm{Al})}{\mathrm{d} t}=-\beta_{i j} \\
& \frac{\mathrm{d} N_{i}(c-\mathrm{Al})}{\mathrm{d} t}=-\beta_{i j} \frac{F}{\left(V_{\mathrm{rat}}-1\right)} \\
& \frac{\mathrm{d} N_{i+1}(c-\mathrm{Al})}{\mathrm{d} t}=+\beta_{i j} \frac{F}{\left(V_{\mathrm{rat}}-1\right)} \\
& \frac{\mathrm{d} M_{j}(\mathrm{~S}-\mathrm{Al})}{\mathrm{d} t}=-\beta_{i j} \mathrm{DSAl}_{j} \\
& \frac{\mathrm{d} M_{i}(\mathrm{~S}-\mathrm{Al})}{\mathrm{d} t}= \\
& -\beta_{i j} \mathrm{DSAl}_{i}+\beta_{i j}\left(1-\frac{F}{\left(V_{\text {rat }}-1\right)}\right)\left(\mathrm{DSAl}_{j}+\mathrm{DSAl}_{i}\right) \\
& \frac{\mathrm{d} M_{i+1}(\mathrm{~S}-\mathrm{Al})}{\mathrm{d} t}=+\beta_{i j} \frac{F}{\left(V_{\mathrm{rat}}-1\right)}\left(\mathrm{DSAl}_{j}+\mathrm{DSAl}_{i}\right) .
\end{aligned}
$$




\section{A1.4 Coagulation kernel}

The coagulation kernels, $K_{i j}$, are calculated following classical theory as detailed in Jacobson (1999). We apply only Brownian coagulation without convective, gravitational, or Van der Waals corrections.

$$
\begin{aligned}
& K_{i j}=\frac{4 \pi\left(r_{i}+r_{j}\right)\left(D_{i}+D_{j}\right)}{\frac{r_{i}+r_{j}}{r_{i}+r_{j}+\left(\delta_{i}^{2}+\delta_{j}^{2}\right)^{1 / 2}}+\frac{4\left(D_{i}+D_{j}\right)}{\left(r_{i}+r_{j}\right)\left(\bar{c}_{i}^{2}+\bar{c}_{j}^{2}\right)^{1 / 2}}} \\
& \delta_{i}=\frac{\left(2 r_{i}+\lambda_{i}\right)^{3}-\left(4 r_{i}^{2}+\lambda_{i}^{2}\right)^{3 / 2}}{6 r_{i} \lambda_{i}}-2 r_{i},
\end{aligned}
$$

where $r_{i}$ represents particle radius, $D_{i}$ represents the particle diffusion coefficient, $\bar{c}_{i}$ represents the thermal velocity of the particle, and $\lambda_{i}$ represents the particle mean free path.

For liquid particles, we use the spherical radius in the calculation of coagulation kernels; for solid particles we use the radius of gyration $R_{\mathrm{g}}$ in the calculation (Maricq, 2007), as this more closely represents the distance over which fractal particles may interact with other particles.

\section{A2 Condensational growth and evaporation}

The rate of $\mathrm{H}_{2} \mathrm{SO}_{4}$ vapor condensation onto sulfate particles or sulfate-coated alumina particles of bin $i$ follows Jacobson (1999) and is given by

$\frac{\mathrm{d} N_{\mathrm{H}_{2} \mathrm{SO}_{4}}}{\mathrm{~d} t}=\frac{-S_{i} N_{i} D_{\mathrm{v}}\left(N_{\mathrm{H}_{2} \mathrm{SO}_{4}}-\alpha N_{\mathrm{H}_{2} \mathrm{SO}_{4}}^{\mathrm{eq}}\right)}{r_{i}}$

where $S_{i}$ represents the surface area of a single particle in bin $i, N_{i}$ the particle number density, $D_{\mathrm{v}}$ is the molecular diffusion coefficient of the $\mathrm{H}_{2} \mathrm{SO}_{4}$ vapor, $\mathrm{N}_{\mathrm{H}_{2} \mathrm{SO}_{4}}$ represents the number density of ambient $\mathrm{H}_{2} \mathrm{SO}_{4}$ gas, and $\mathrm{N}_{\mathrm{H}_{2} \mathrm{SO}_{4}}^{\text {eq }}$, the equilibrium $\mathrm{H}_{2} \mathrm{SO}_{4}$ number density above a liquid $\mathrm{H}_{2} \mathrm{SO}_{4}$ surface. $\alpha$ is the Kelvin effect correction term, representing the saturation vapor pressure over a curved surface relative to that over a flat surface, given by

$\alpha=\exp \left(\frac{2 \sigma_{\mathrm{p}} \mu_{\mathrm{p}}}{r_{i} R^{*} T \rho_{\mathrm{p}}}\right)$

$\alpha$ is a function of the surface tension of the $\mathrm{H}_{2} \mathrm{SO}_{4}$ liquid, $\sigma_{\mathrm{p}}$, the average molecular weight of the liquid, $\mu_{\mathrm{p}}$, the particle radius, $r_{i}$, gas constant, $R^{*}$, temperature, $T$, and liquid solution density, $\rho_{\mathrm{p}}$. The diffusion coefficient is defined as

$$
\begin{aligned}
& D_{\mathrm{v}}=\frac{3}{8 d^{2} N_{\mathrm{air}}}\left(\frac{k_{B} T A_{V}}{2 \pi \mu_{\mathrm{H}_{2} \mathrm{SO}_{4}}} \frac{\mu_{\mathrm{air}}+\mu_{\mathrm{H}_{2} \mathrm{SO}_{4}}}{\mu_{\text {air }}}\right)^{0.5} \omega \\
& \omega=\left\{1+\left[\frac{1.3333+0.71 K_{n}^{-1}}{1+K_{n}^{-1}},\right] K_{n}\right\}^{-1}
\end{aligned}
$$

where $d$ is the diameter of a gas molecule, $k_{B}$ is Boltzman's constant, and $A_{V}$ is Avogadro's number, $\omega$ is a correction term for collision geometry, and $K_{n}$ is the Knudsen number. We assume an accommodation coefficient of 1.0. We use the spherical radius in the calculations for pure sulfuric acidwater particles, and the radius of gyration, $R_{\mathrm{g}}$, increased by the coating thickness, for the sulfate-coated solid particles. However, for the curvature term $\alpha$, we use the radius of the monomers composing the fractal particles increased by the coating thickness. The particle surface area for fractal particles is as described in Sect. 2 of this paper.

In the case of pure liquid $\mathrm{H}_{2} \mathrm{SO}_{4}-\mathrm{H}_{2} \mathrm{O}$ particles, condensation increases the particle radius and shifts mass into larger size bins, much as the coagulation formulation described above distributes mass between two bins when a particle's radius would fall between two bins. For sulfate-coated alumina particles, the bin is defined by the radius of the alumina particle only, so the size bin remains constant while the mass of sulfate associated with that bin increases. Evaporation occurs via the identical equations when $N_{\mathrm{H}_{2} \mathrm{SO}_{4}}$ is less than $\alpha N_{\mathrm{H}_{2} \mathrm{~S}_{4}}^{\mathrm{eq}}$ and $\frac{\mathrm{d} N_{\mathrm{H}_{2} \mathrm{SO}_{4}}}{\mathrm{~d} t}$ becomes positive. This occurs above about $35 \mathrm{~km}$ for sulfuric acid particles. 
Author contributions. D. Keith conceived this study and provided overall scientific direction. D. Weisenstein developed the solidliquid aerosol model and performed the 2-D calculations. D. Keith performed the shortwave radiative forcing calculations, while J. Dykema calculated the heating rates with longwave and shortwave contributions.

Acknowledgements. Funding for this study was provided by a grant from the Fund for Innovative Climate and Energy Research (FICER). The authors would like to thank Frank Keutsch and Sebastian Eastham for insightful comments on earlier drafts of this paper. The authors would also like to thank two anonymous reviewers for constructive suggestions which have improved this paper.

Edited by: F. Khosrawi

\section{References}

Anderson, S. B., Weatherhead, E. C., Stevermer, A., Austin, J., Brühl, C., Fleming, E. L., de Grandpre, J., Grewe, V., Isaksen, I., Pitari, G., Portmann, R. W., Rognerud, B., Rosenfield, J. E., Smyshlyaev, S., Nagashima, T., Velders, G. J. M., Weisenstein, D. K., and Xia, J.: Comparison of recent modeled and observed trends in total column ozone, J. Geophys. Res., 111, D02303, doi:10.1029/2005JD006091, 2006.

Blackstock, J. J., Battisti, D. S., Caldeira, K., Eardley, D. M., Katz, J. I., Keith, D. W., Patrinos, A. A. N., Schrag, D. P., Socolow, R. H., and Koonin, S. E.: Climate Engineering Responses to Climate Emergencies, Novim, available at: http://arxiv.org/pdf/ 0907.5140 (last access: 21 October 2015), 2009.

Bohren, C. F. and Huffman, D. R.: Absorption and scattering of light by small particles, John Wiley \& Sons, 2008.

Brock, C. A., Hamill, P., Wilson, J. C., Jonsson, H. H., and Chang, K. R.: Particle formation in the upper tropical troposphere: A source of nuclei for the stratospheric aerosol, Science, 270, 1650-1653, 1995.

Charlson, R. J., Langner, J., Rodhe, H., Leovy, C. B., and Warren, S. G.: Perturbation of the northern hemisphere radiative balance by backscattering from anthropogenic sulfate aerosols, Tellus A, 43, 152-163, 1991.

Cirisan, A., Spichtinger, P., Luo, B. P., Weisenstein, D. K., Wernli, H., Lohmann, U., and Peter, T.: Microphysical and radiative changes in cirrus clouds by geoengineering the stratosphere, J. Geophys. Res., 118, 4533-4548, doi:10.1002/jgrd.50388, 2013.

Clough, S. A., Shephard, M. W., Mlawer, E. J., Delamere, J. S., Iacono, M. J., Cady-Pereira, K., Boukabara, S., and Brown, P. D.: Atmospheric radiative transfer modeling: a summary of the AER codes, J. Quant. Spectrosc. Ra., 91, 233-244, 2005.

Curry, C. L., Sillmann, J., Bronaugh, D., Alterskjaer, K., Cole, J. N. S., Ji, D., Kravitz, B., Kristjansson, J. E., Moore, J. C., Muri, H., Niemeier, U., Robock, A., Tilmes, S., and Yang, S.: A multimodel examination of climate extremes in an idealized geoengineering experiment, J. Geophys. Res., 119, 3900-3923, doi:10.1002/2013JD020648, 2014.

Danilin, M. Y., Shia, R.-L., Ko, M. K. W., Weisenstein, D. K., Sze, N. D., Lamb, J. J., Smith, T. W., Lohn, P. D., and Prather, M. J.:
Global stratospheric effects of the alumina emissions by solidfueled rocket motors, J. Geophys. Res., 106, 12727-12738, 2001.

De Richter, R., and Caillol, S.: Fighting global warming: The potential of photocatalysis against $\mathrm{CO}_{2}, \mathrm{CH}_{4}, \mathrm{~N}_{2} \mathrm{O}$, CFCs, tropospheric $\mathrm{O}_{3}, \mathrm{BC}$ and other major contributors to climate change, J. Photoch. Photobio. C, 12, 1-19, doi:10.1016/j.jphotochemrev.2011.05.002, 2011.

Dvortsov, V. L., Geller, M. A., Yudin, V. A., and Smyshlyaev, S. P.: Parameterization of the convective transport in a twodimensional chemistry-transport model and its validation with radon 222 and other tracer simulations, J. Geophys. Res., 103, 22047-22062, doi:10.1029/98JD02084, 1998.

Edwards, D. F. and Philipp, H. R.: "Cubic carbon (diamond)", in: Handbook of Optical Constants of Solids, edited by: Palik, E., Academic Press Inc., San Diego, CA, USA, 1985.

English, J. M., Toon, O. B., and Mills, M. J.: Microphysical simulations of sulfur burdens from stratospheric sulfur geoengineering, Atmos. Chem. Phys., 12, 4775-4793, doi:10.5194/acp-12-47752012, 2012.

Ferraro, A. J., Highwood, E. J., and Charlton-Oerez, A. J.: Stratospheric heating by potential geoengineering aerosols, Geophys. Res. Lett., 38, L24706, doi:10.1029/2011GL049761, 2011.

Fleming, E. L., Jackman, C. H., Stolarski, R. S., and Considine, D. B.: Simulation of stratospheric tracers using an improved empirically-based two-dimensional model transport formulation, J. Geophys. Res., 104, 23911-23934, 1999.

Filippov, A. V., Zurita, M., and Rosner, D. E.: Fractal-like aggregates: Relation between morphology and physical properties, J. Colloid Interf. Sci., 229, 261-273, 2000.

Hamill, P., Jensen, E. J., Russell, P, B., and Bauman, J. J.: The life cycle of stratospheric aerosol particles, B. Am. Meteor. Soc., 78, 1395-1410, 1997.

Hanson, D. and Mauersberger, K.: Laboratory studies of the nitric acid trihydrate: Implications for the south polar stratosphere, Geophys. Res. Lett., 15, 855-858, 1988.

Heckendorn, P., Weisenstein, D., Fueglistaler, S., Luo, B. P., Rozanov, E., Schraner, M., Thomason, L. W., and Peter, T.: The impact of geoengineering aerosols on stratospheric temperature and ozone, Environ. Res. Lett., 4, 045108, doi:10.1088/17489326/4/4/045108, 2009.

Hinklin, T., Toury, B., Gervais, C., Babonneau, F., Gislason, J. J., Morton, R. W., and Laine, R. M.: Liquid-feed flame spray pyrolysis of metalloorganic and inorganic alumina sources in the production of nanoalumina powders, Chem. Mater., 16, 21-30, doi:10.1021/cm021782t, 2004.

Jackman, C. H., Considine, D. B., and Fleming, E. L.: A global modeling study of solid rocket aluminum oxide emission effects on stratospheric ozone, Geophys. Res. Lett., 25, 907-910, 1998.

Jacobson, M. Z.: Fundamentals of Atmospheric Modeling, Cambridge University Press, 1999.

Johnson, C. P., Li, X., and Logan, B. E.: Settling velocities of fractal aggregates, Environ. Sci. Technol., 30, 1911-1918, 1996.

Kajino, M. and Kondo, Y.: EMTACS: Development and regionalscale simulation of a size, chemical, mixing type, and soot shape resolved atmospheric particle model, J. Geophys. Res., 116, D02303, doi:10.1029/2010JD015030, 2011.

Karasev, V. V., Onishchuk, A. A., Glotov, O. G., Baklinov, A. M., Zarko, V. E., and Panfilov, V. N.: Charges and fractal properties 
of nanoparticles - Combusion products of aluminum agglomerates, Combust. Explo. Shock+, 37, 734-736, 2001.

Karasev, V. V., Onischuk, A. A., Glotov, O. G., Baklanov, A. M., Maryasov, A. G., Zarko, V. E., Panfilov, V. N, Levykin, A. I., and Sabelfeld, K. K.: Formation of charged aggregates of $\mathrm{Al}_{2} \mathrm{O}_{3}$ nanoparticles by combustion of aluminum droplets in air, Combust. Flame, 138, 40-54, 2004.

Keith, D. W.: Photophoretic levitation of engineered aerosols for geoengineering, Proc. Natl. Acad. Sci. USA, 107, 16428-16431, doi:10.1073/pnas.1009519107, 2010.

Kirk-Davidoff, D. B, Hintsa, E. J., Anderson, J. G., and Keith, D. W.: The effect of climate change on ozone depletion through changes in stratospheric water vapour, Nature, 402, 399-401, 1999.

Kravitz, B., MacMartin, D. G., and Caldeira, K.: Geoengineering: Whiter skies?, Geophys. Res. Lett., 39, L11801, doi:10.1029/2012GL051652, 2012.

Kravitz, B., MacMartin, D. G., Robock, A., Rasch, P. J., Ricke, K. L., Cole, J. N. S., Curry, C. L., Irvine, P. J., Ji, D., Keith, D. W., Kristjansson, J. E., Moore, J. C., Muri, H., Singh, B., Tilmes, S., Watanabe, S., Yang, S., and Yoon, J.-H.: A multi-model assessment of regional climate disparities caused by solar geoengineering, Environ. Res. Lett., 9, 074013, doi:10.1088/17489326/9/7/074013, 2014.

Krueger, A.: Diamond nanoparticles: Jewels for chemistry and physics, Adv. Mater., 20, 2445-2449, doi:10.1002/adma.200701856, 2008.

Kuebbeler, M., Lohmann, U., and Feichter, J.: Effects of stratospheric sulfate aerosol geo-engineering on cirrus clouds, Geophys. Res. Lett., 39, L23803, doi:10.1029/2012GL053797, 2012.

Lawrence, C. R. and Neff, J. C.: The contemporary physical and chemical flux of aeolian dust: A synthesis of direct measurements of dust deposition, Chem. Geol., 267, 46063, doi:10.1016/j.chemgeo.2009.02.005, 2009.

Maricq, M. M.: Coagulation dynamics of fractal-like soot aggregates, J. Aerosol Sci., 38, 141-156, 2007.

Maricq, M. M. and Nu, N.: The effective density and fractal dimension of soot particles from premixed flames and motor vehicle exhaust, J. Aerosol Sci., 35, 1251-1274, 2004.

Marti, J. and Mauersberger, K.: A survey and new measurements of ice vapor pressure at temperatures between 170 and $250 \mathrm{~K}$, Geophys. Res. Lett., 20, 363-366, 1993.

McClellan, J., Keith, D. W., and Apt, J.: Cost analysis of stratospheric albedo modification delivery systems, Environ. Res. Lett., 7, 034019, doi:10.1088/1748-9326/7/3/034019, 2012.

Mercado, L. M., Bellouin, N., Sitch, S., Boucher, O., Huntiongford, C., Wild, M., and Cox, P. M.: Impact of changes in diffuse radiation on the global land carbon sink, Nature, 458, 1014-1018, doi:10.1038/nature07949, 2009.

Mikhailov, E. F., Vlasenko, S. S., Podgorny, I. A., Ramanathan, V., and Corrigan, C. E.: Optical properties of soot-water drop agglomerates: An experimental study, J. Geophys. Res., 111, D07209, doi:10.1029/2005JD006389, 2006.

Mlawer, E. J., Taubman, S. J., Brown, P. D., Iacono, M. J., and Clough, S. A.: RRTM, a validated correlated-k model for the longwave, J. Geophys. Res., 102, 16663-16682, 1997.

Molina, M. J., Molina, L. T., Zhang, R., Meads, R. F., and Spencer, D. D.: The reaction of $\mathrm{ClONO}_{2}$ with $\mathrm{HCl}$ on aluminum oxide,
Geophys. Res. Lett., 24, 1619-1622, doi:10.1029/97GL01560, 1997.

Moreno-Cruz, J., Ricke, K., and Keith, D. W.: A simple model to account for regional inequalities in the effectiveness of solar radiation management, Climatic Change, 110, 649-668, doi:10.1007/s10584-011-0103-z, 2011.

Niemeier, U., Schmidt, H., and Timmreck, C.: The dependency of geoengineered sulfate aerosol on the emission strategy, Atmos. Sci. Lett., 12, 189-194, doi:10.1002/asl.304, 2011.

Pierce, J. R., Weisenstein, D. K., Heckendorn, P., Peter, T., and Keith, D. W.: Efficient formation of stratospheric aerosol for climate engineering by emission of condensible vapor from aircraft, Geophys. Res. Lett., 37, L18805, doi:10.1029/2010GL043975, 2010.

Pitari, G., Aquila, V., Kravitz, B., Robock, A., Watanabe, S., Cionni, I., De Luca, N., Di Genova, G., Mancini, E., and Tilmes, S.: Stratospheric ozone response to sulfate geoengineering: Results from the Geoengineering Model Intercomparison Project (GeoMIP), J. Geophys. Res., 119, 2629-2653, doi:10.1002/2013JD020566, 2014.

Pope, F. D., Braesicke, P., Grainger, R. G., Kalberer, M., Watson, I. M., Davidson, P. J., and Cox, R. A.: Stratospheric aerosol particles and solar-radiation management, Nature Climate Change, 2, 713-719, doi:10.1038/NCLIMATE1528, 2012.

Rannou, P., McKay, C. P., Botet, R., and Cabane, M.: Semiempirical model of absorption and scattering by isotropic fractal aggregates of spheres, Planet. Space Sci., 47, 385-396, 1999.

Rasch, P. J., Crutzen, P. J., and Coleman, D. B.: Exploring the geoengineering of climate using stratospheric sulfate aerosols: the role of particle size, Geophys. Res. Lett., 35, L02809, doi:10.1029/2007GL032179, 2008.

Rinsland, C. P., Weisenstein, D. K., Ko, M. K. W., Scott, C. J., Chiou, L. S., Mahieu, E., Zander, R., and Demoulin, P.: PostMount Pinatubo eruption ground-based infrared stratospheric column measurements of $\mathrm{HNO}_{3}, \mathrm{NO}$, and $\mathrm{NO}_{2}$ and their comparison with model calculations, J. Geophys. Res., 108, 4437, doi:10.1029/2002JD002965, 2003.

Ross, M. N. and Sheaffer, P. M.: Radiative forcing caused by rocket engine emissions, Earth's Future, 2, 177-196, doi:10.1002/2013EF000160, 2014.

Sander, S. P., Friedl, R. R., Barker, J. R., Golden, D. M., Kurylo, M. J., Wine, P. H., Abbatt, J. P. D., Burkholder, J. B., Kolb, C. E., Moortgat, G. K., and Huie, R. E.: Chemical kinetics and photochemical data for use in atmospheric studies, Evaluation No. 17, JPL Publication 10-6, 2011.

Seinfeld, J. H. and Pandis, S. N.: Atmospheric Chemistry and Physics, John Wiley and Sons, Inc., 2006.

Shi, Q., Jayne, J. T., Kolb, C. E., Worsnop, D. R., and Davidovits, P.: Kinetic model for reaction of $\mathrm{ClONO}_{2}$ with $\mathrm{H}_{2} \mathrm{O}$ and $\mathrm{HCl}$ and $\mathrm{HOCl}$ with $\mathrm{HCl}$ in sulfuric acid solutions, J. Geophys. Res., 106, 24259-24274, 2001.

Shrand, A. M., Huang, H., Carlson, C., Schlager, J. J., Osawa, E., Hussain, S. M., and Dai, L.: Are diamond nanoparticles cytotoxic? J. Phys Chem. B, 111, 2-7, doi:10.1021/jp066387v, 2007.

Solomon, S.: Stratospheric ozone depletion: a review of concepts and history, Rev. Geophys., 37, 275-316, doi:10.1029/1999RG900008, 1999.

SPARC: SPARC Report No. 4, Assessment of Stratospheric Aerosol Properties (ASAP), WCRP-124 WMO/TD No. 1295, 
SPARC Report No. 4, edited by: Thomason, L. and Peter, Th., WMO, 2006.

Tabazadeh, A., Toon, O. B., Cleg, S. L., and Hamill, P.: A new parameterization of $\mathrm{H}_{2} \mathrm{SO}_{4} / \mathrm{H}_{2} \mathrm{O}$ aerosol composition: Atmospheric implications, Geophys. Res., Lett., 24, 1931-1934, 1997.

Tang, M. J., Camp, J. C. J., Rkiouak, L., McGregor, J., Watson, I. M., Cox, R. A., Kalberer, M., Ward, A. D., and Pope, F. D.: Heterogeneous Interaction of $\mathrm{SiO}_{2}$ with $\mathrm{N}_{2} \mathrm{O}_{5}$ : Aerosol Flow Tube and Single Particle Optical Levitation-Raman Spectroscopy Studies, J. Phys. Chem. A, 118, 8817-8827, 2014a.

Tang, M. J., Telford, P. J., Pope, F. D., Rkiouak, L., Abraham, N. L., Archibald, A. T., Braesicke, P., Pyle, J. A., McGregor, J., Watson, I. M., Cox, R. A., and Kalberer, M.: Heterogeneous reaction of $\mathrm{N}_{2} \mathrm{O}_{5}$ with airborne $\mathrm{TiO}_{2}$ particles and its implication for stratospheric particle injection, Atmos. Chem. Phys., 14, 6035-6048, doi:10.5194/acp-14-6035-2014, 2014b.

Teller, E., Wood, L., and Hyde, R.: Global Warming and Ice Ages: I. Prospects for Physics-Based Modulation of Global Change, Lawrence Livermore National Laboratory Publication UCRLJC-128715, 18 pp., 1997.

Tilmes, S., Muller, R., and Salawitch, R.: The sensitivity of polar ozone depletion to proposed geoengineering schemes, Science, 320, 1201-1204, doi:10.1126/science.1153966, 2008.

Tilmes, S., Garcia, R. R., Kinnison, D. E., Gettelman, A., and Rasch, P. J.: Impact of geoengineered aerosols on the troposphere and stratosphere, J. Geophys. Res., 114, D12305, doi:10.1029/2008JD011420, 2009.

Tilmes, S., Kinnison, D. E., Garcia, R. R., Salawitch, R., Canty, T., Lee-Taylor, J., Madronich, S., and Chance, K.: Impact of very short-lived halogens on stratospheric ozone abundance and UV radiation in a geo-engineered atmosphere, Atmos. Chem. Phys., 12, 10945-10955, doi:10.5194/acp-12-10945-2012, 2012.

Thomas, M. E. and Tropf, W. J.: Aluminum Oxide $\left(\mathrm{Al}_{2} \mathrm{O}_{3}\right)$ Revisited, in: Handbook of Optical Constants of Solids, Vol. 3, edited by: Palik, E. D., Academic Press Inc., St. Louis, MO, USA, 1997.
Tsuzuki, T. and McCormick, P. G.: Mechanochemical synthesis of nano particles, J. Mater. Sci., 39, 5143-5146, 2004.

U.S. Geological Survey (USGS): 2012 Minerals Yearbook: Bauxite and Alumina, US Department of the Interior, Washington, DC, available at: http://minerals.usgs.gov/minerals/pubs/commodity/ bauxite/myb1-2012-bauxi.pdf (last access: 21 October 2015), May 2014.

Weisenstein, D. K., Yue, G. K., Ko, M. K. W., Sze, N.-D., Rodriguez, J. M., and Scott, C. J.: A two-dimensional model of sulfur species and aerosols, J. Geophys. Res., 102, 13019-13035, 1997.

Weisenstein, D. K., Ko, M. K. W., Dyominov, I. G., Pitari, G., Picciardulli, L., Visconti, G., and Bekki, S.: The effects of sulfur emission from HSCT aircraft: A 2-D model intercomparison, J. Geophys. Res., 103, 1527-1547, 1998.

Weisenstein, D. K., Eluszkiewicz, J., Ko, M. K. W., Scott, C. J., Jackman, C. H., Fleming, E. L., Considine, D. B., Kinnison, D. E., Connell, P. S., and Rotman, D. A.: Separating chemistry and transport effects in 2-D models, J. Geophys. Res., 109, D18310, doi:10.1029/2004JD004744, 2004.

Weisenstein, D. K., Penner, J. E., Herzog, M., and Liu, X.: Global 2D intercomparison of sectional and modal aerosol modules, Atmos. Chem. Phys., 7, 2339-2355, doi:10.5194/acp-7-2339-2007, 2007.

Wilton, D. J., Hewitt, C. N., and Beerling, D. J.: Simulated effects of changes in direct and diffuse radiation on canopy scale isoprene emissions from vegetation following volcanic eruptions, Atmos. Chem. Phys., 11, 11723-11731, doi:10.5194/acp11-11723-2011, 2011.

Wiscombe, W. J. and Grams, G. W.: The backscattered fraction in two-stream approximations, J. Atmos. Sci., 33, 2440-2451, 1976. 